\title{
El Periodo Intermedio Tardío en Cajamarquilla a partir de las evidencias del sector Tello
}

\section{The Late Intermediate Period in Cajamarquilla based on the evi- dence of the Tello sector}

\section{Yomira Silvia Huaman Santillan}

https://orcid.org/0000-0001-5209-9514 Universidad Nacional Mayor de San Marcos yomira.huaman@unmsm.edu.pe

\section{RESUMEN}

El presente artículo aborda la problemática de la ocupación del Periodo Intermedio Tardío en el sitio arqueológico de Cajamarquilla, ubicado dentro de la ciudad de Lima Metropolitana, uno de los asentamientos más extensos de la costa de Lima, pero a la vez uno de los menos investigados. Con el presente estudio se busca definir la importancia que adquirió Cajamarquilla durante este periodo, a partir del análisis de la arquitectura de tapiales que aflora en la superficie, la distribución espacial de las unidades arquitectónicas, su funcionalidad. Con el resultado de este trabajo de investigación se logrará tener un mayor conocimiento sobre las prácticas culturales desarrolladas en periodos prehispánicos tardíos en Cajamarquilla, sus interacciones con otros sitios del valle del Rímac, las estrategias productivas que tuvo y la situación jerárquica al momento de la llegada de los incas y la anexión de este territorio al Tawantinsuyu.

Palabras clave: valle medio del Rímac; tapial; Intermedio Tardío; arquitectura; sector o conjunto. 


\section{ABSTRACT}

This research project addresses the problem of the occupation of the Late Intermediate Period in the archaeological site of Cajamarquilla, located within the city of Metropolitan Lima, one of the most extensive settlements on the coast of Lima, but at the same time one of the less researched. The present study seeks to define the importance that Cajamarquilla acquired during this period, from the analysis of the architecture of mud walls that appear on the surface, the spatial distribution of the architectural units, their functionality. With the result of this research work, it will be possible to have a greater knowledge about the cultural practices developed in late pre-Hispanic periods in Cajamarquilla, their interactions with other sites in the Rímac valley, the productive strategies they had and the hierarchical situation at the time of arrival of the Incas and the annexation of this territory to the Tawantinsuyu.

Keywords: middle Rímac valley; mud or adobon; Late Intermediate; architecture; sector or complex.

ReCibiDO: 20/02/2021 - ACePTADO: 25/03/2021 - Publicado: 25/06/2021

\section{INTRODUCCIÓN}

El presente artículo es resultado del trabajo de investigación financiado en el tercer concurso del Programa de Promoción de trabajo de investigación para optar el grado de Bachiller, por parte del Vicerrectorado de Investigación y Posgrado de la Universidad Nacional Mayor de San Marcos, titulado "Cajamarquilla, identificación de su máxima extensión a través de la arquitectura del tapial en el Periodo Intermedio Tardío", aprobado mediante Resolución Rectoral 016948-2020-R/ UNMSM de fecha 11 de noviembre de 2020, proyecto registrado por la Escuela Profesional de Arqueología (oficio del 21 de setiembre de 2020), bajo la asesoría del Dr. Pieter van Dalen Luna.

El objetivo del presente estudio fue el establecer las dimensiones, áreas de ocupación e importancia de Cajamarquilla durante el Periodo Intermedio Tardío, en base al análisis de la arquitectura y organización espacial del sector Julio C. Tello. La investigación es de tipo deductiva, descriptiva, comparativa y exploratoria.

\section{UBICACIÓN DEL SITIO}

El sitio arqueológico de Cajamarquilla está ubicado en la margen derecha del valle medio del río Rímac. El área delimitada del sitio por el Ministerio de Cultura es de 1'401.172.93 $\mathrm{m}^{2}$; limitando con una gran cantidad de asentamientos humanos: por el norte los Asentamientos Humanos Casa Huerta La Campiña, Santa Cruz y Paraíso; por el este el Asentamiento Humano El Ayllu (conocido como La Chacra); por el sur 
se encuentra la quebrada Jicamarca (conocido como Huayco), y por el oeste el canal de Nievería, que bordea algunos campos de cultivo. Se encuentra ubicado en el distrito de Lurigancho - Chosica, provincia de Lima, región Lima. Cajamarquilla se encuentra a 393 m s. n. m., a 24 km del litoral del Pacífico y a 3 km del río Rímac. Se encuentra ubicado en la coordenada UTM: 292096E y 8673948N.

\section{CARACTERÍSTICAS GEOGRÁFICAS Y ECOLÓGICAS DEL SITIO}

Al sur del sitio arqueológico de Cajamarquilla (no más de $200 \mathrm{~m}$ ) se encuentra la quebrada del Huaycoloro o conocido también como Jicamarca o Río Seco, donde discurren los aluviones, inundaciones o huaycos (lloqllas) que se cargan cuando ocurren los fenómenos del Niño o ENSO, como sucedió en los años 1988, 2002 y 2017. Como consecuencia de este fenómeno, Cajamarquilla se encuentra situado sobre una llanura que Villar Córdova (1935), lo mencionó con el nombre de "pumapampa", la cual tiene conexión con la quebrada de Jicamarca y esta llanura sufrió un proceso de cambio; la corriente de los huaycos, en su trayecto desde la provincia de Huarochirí hasta pasar por el mismo sitio arqueológico, trae una mezcla de lodo, piedra y sedimentos, que ha destruido en los últimos cinco siglos gran parte de Cajamarquilla, pues queda destruido y cubierto con capa gruesa de tierra. Este proceso de arrastre de material aluvial se ha dado siempre, incluso durante periodos arqueológicos, como se puede evidenciar en los estratos arqueológicos con una delgada capa de yapana, que en algún momento cubrió parte del sitio mientras estaba ocupado. Por su parte, el canal de Nievería pasaba muy cerca del sitio (y sigue activo hasta el día de hoy), para el proceso del material constructivo.

El sitio se ubica en la región costeña (Pulgar, 1946) o ecorregión Desierto del Pacífico (Brack, 1987). Tiene un clima caluroso en verano durante los meses de diciembre a marzo y con neblinas en invierno en los meses de mayo a setiembre, lo que propicia a la aparición de lomas que cubren las laderas de los cerros de los Asentamientos Humanos de Casa Huerta, La Campiña, Santa Cruz y otros más cercanos.

Sin embargo, a pesar de encontrarse ubicado a pocos metros de altitud y tan cerca del litoral, no se ubica propiamente en el valle bajo del Rímac, sino en el valle medio bajo, muy cerca del cono de deyección que se inicia en la localidad de Vitarte (ver figuras 01, 02 y 03).

\section{EL VALLE MEDIO - BAJO DEL RÍMAC}

El valle del Rímac se encuentra en la Costa Central, en su recorrido la cuenca del río Rímac, que pertenece al sistema hidrográfico del Océano Pacífico, tiende a cambiar su trazo en su recorrido, debido a la diferencia de relieve, presentando una forma de abanico de deyección (Bueno, 1994). El valle medio del Rímac se inicia en San Bartolomé (Huarochirí) extendiéndose hasta el cono de deyección ubicado en 


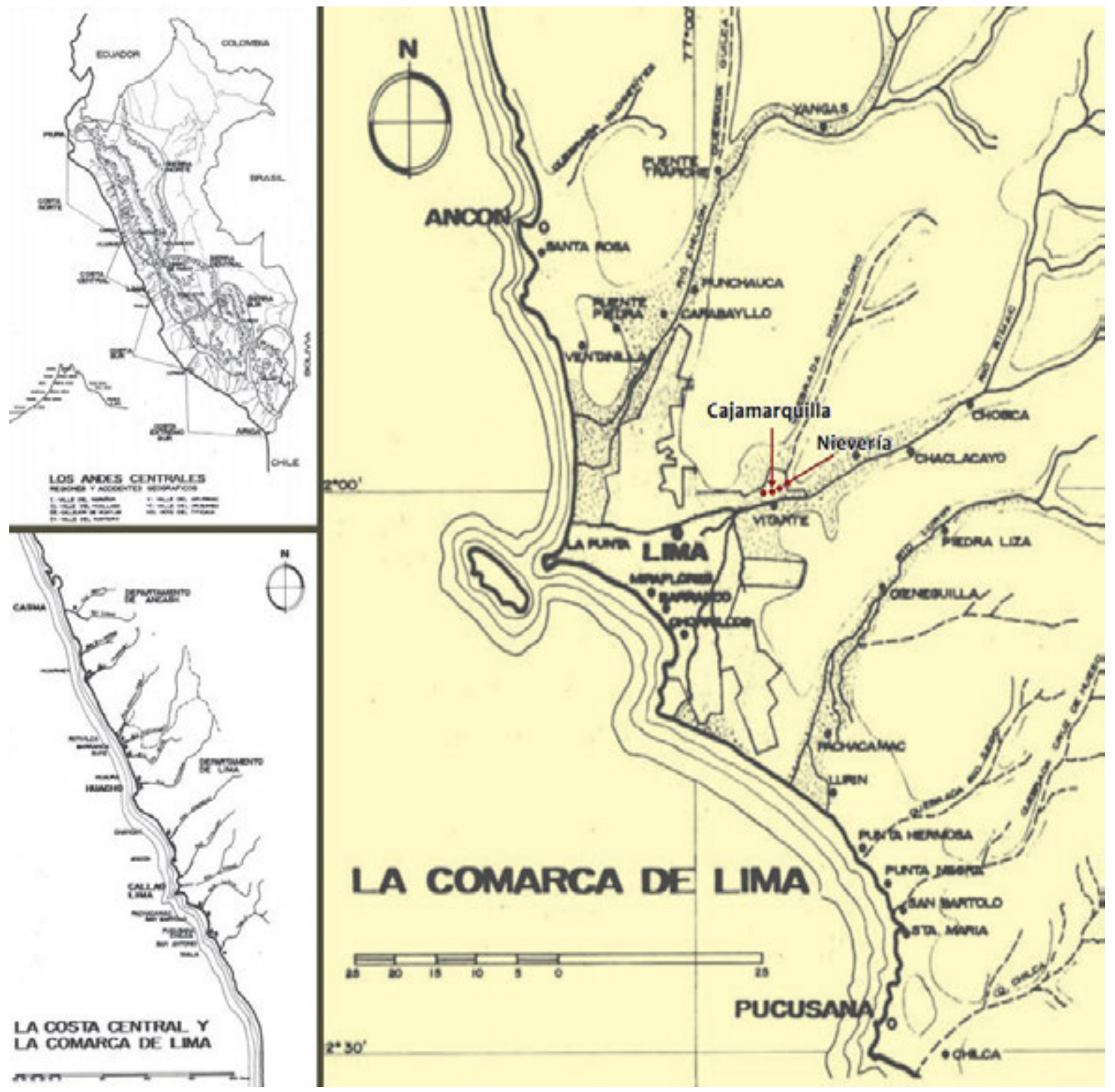

Figura 01. Costa Central con la ubicación de Cajamarquilla. Fuente: Agurto Calvo, Santiago; Lima Prehispánica. Lima, 1983. 


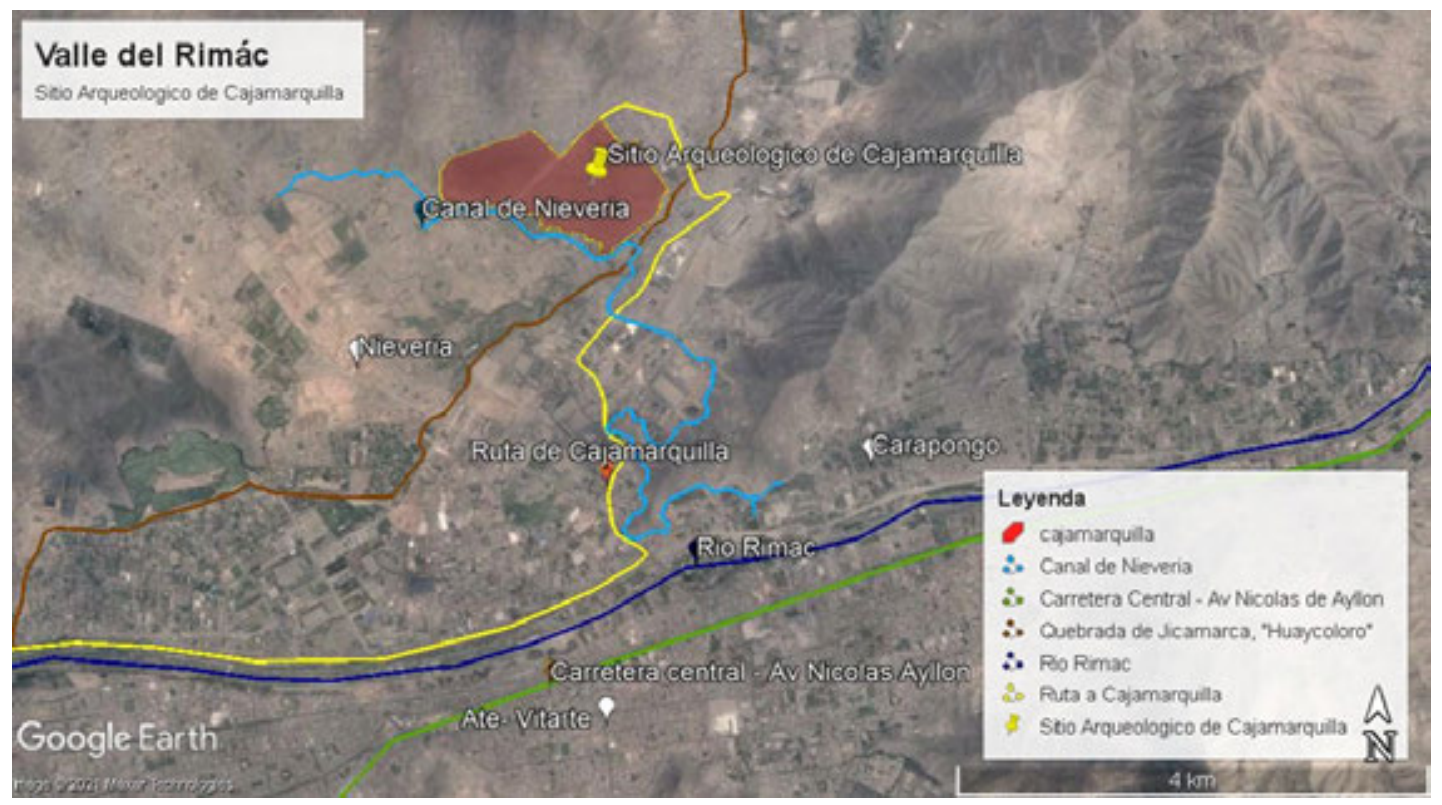

Figura 02. Valle del río Rímac, en la margen derecha se encuentra el complejo de Cajamarquilla. Fuente: Google earth

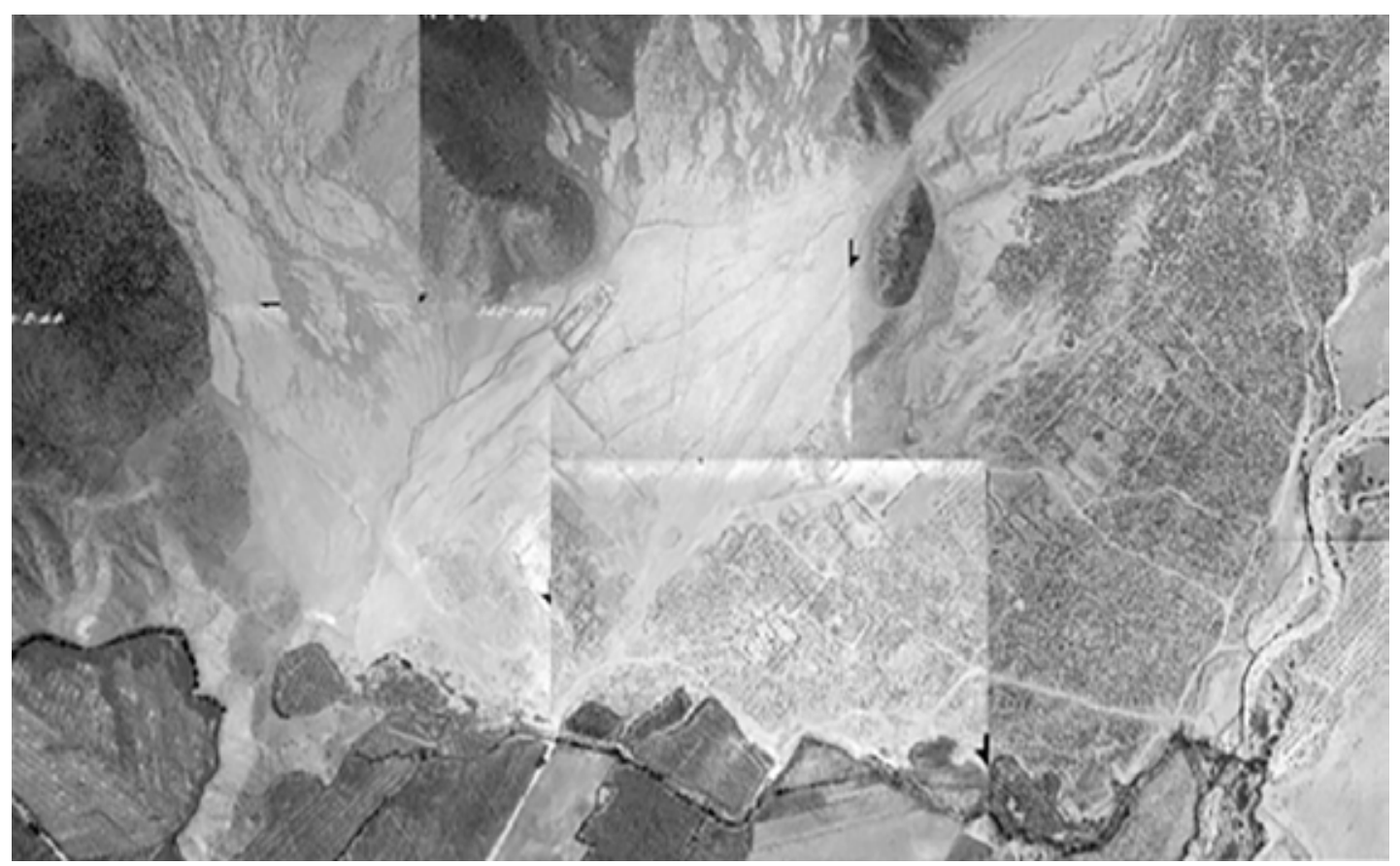

Figura 03. Fotografía Aérea de Cajamarquilla (1944). Fuente: Servicio Aerofotográfico Nacional (SAN). 
Vitarte, caracterizado por su típica forma en "V". El valle medio tiene dos zonas bien diferenciadas, el valle medio - alto, también conocido como chaupiyunga (van Dalen, 2012c), por su clima caluroso y territorio demasiado escarpado, donde los contrafuertes se elevan casi desde el cauce mismo del río; y el valle medio bajo, donde los terrenos planos contiguos al río se ensanchan ligeramente. El valle medio bajo se inicia en la localidad de Chosica, caracterizado por ser un valle frutícola y de panllevar, en las últimas décadas estas áreas de cultivo han retrocedido considerablemente por el avance de las urbanizaciones.

\section{CANAL DE NIEVERÍA}

Se encuentra ubicado en la margen derecha del valle del Rímac, es un canal principal para la zona de Huachipa (señorío Guachipa) con una extensión de $7.7 \mathrm{~km}$, que abarca un área de irrigación de 1513.8 hectáreas; según Lasarte (1919), (citado en: Narváez, 2013, p. 63) bordea el sitio arqueológico de Cajamarquilla por su lado sur.

El sistema de irrigación en el valle medio del Rímac y en los distintos valles, es muy importante para los sitios arqueológicos prehispánicos de la Costa Central, para el aprovechamiento de diversas actividades como el uso doméstico, la agricultura, etc. El valle del Rímac es una zona árida, sus principales canales tuvieron que ser expandidos para una mejor administración de las aguas del río Rímac en beneficio a estas culturas prehispánicas, como es el caso del canal de Nievería, junto a los demás canales (secundario, terciarios, etc.), formando los llamados "valles artificiales":

"En Huachipa había tres canales provenientes del río Rímac, llamados, de este a oeste, Nievería, Huachipa y Mogollón (Elmore 1904; Lasarte 1919: 270). El canal de Nievería se dirige desde la toma hacia el noroeste, pasa por el norte de la población de Carapongo, continúa hacia el oeste por la falda de la cadena del cerro Matabuey, en donde se encuentra con aguas del canal de Carapongo que viene de más arriba, gira luego hacia el noroeste para después enrumbar al noreste y luego de cruzar el usualmente seco río Huaycoloro a través de una canoa de riego bordea el complejo arqueológico Cajamarquilla por el sur y llega hasta la zona conocida como Media Luna." (Narváez, 2013, p. 35).

El canal de Nievería, es uno de los factores determinantes para la construcción o ampliación del sitio arqueológico de Cajamarquilla, que tiene una amplia extensión de material arquitectónico a base de muros de tapiales y adobones.

\section{DESCRIPCIÓN DEL SITIO DE CAJAMARQUILLA}

Cajamarquilla está conformado por diversos sectores o grupos arquitectónicos, siendo los más representativos los de: Laberinto, Julio C. Tello, Sestieri y Villar Córdova. La clasificación o distribución de los sectores (mal llamados grupos arquitec- 
tónicos) del sitio arqueológico de Cajamarquilla, ha sido planteado de manera más clara por Alberto Bueno (1974-75), que los agrupa por sus características arquitectónicas o posibles funciones. Los más representativos son:

Cuadro 1. Cuadro de síntesis de los sectores o conjuntos arquitectónicos del sitio arqueológico de Cajamarquilla.

\begin{tabular}{|l|l|}
\hline \multicolumn{2}{|c|}{ GRUPOS ARQUITECTÓNICOS } \\
\hline $\begin{array}{l}\text { Grupos con altos edificios, pirámides domi- } \\
\text { nantes. }\end{array}$ & $\begin{array}{l}\text { - Grupo Villar Córdova. } \\
\text { - Grupo Sestieri. }\end{array}$ \\
\hline Grupos con pequeña pirámide dominante. & $\begin{array}{l}\text { - Grupo Jorgue Muelle. } \\
\text { - Grupo Kroeber. } \\
\text { - Grupo D 'Harcourt. }\end{array}$ \\
\hline Grupos constructivos sin pirámide. & $\begin{array}{l}\text { - Grupo Laberinto. } \\
\text { - Grupo Este. } \\
\text { - Grupo Norte. } \\
\text { - Grupo Sur y Suroeste. }\end{array}$ \\
\hline Servicios & $\begin{array}{l}\text { - Cementerios Nievería y los "Cerros Nor- } \\
\text { te". } \\
\text { - Recintos en tumbas abotelladas. } \\
\text { - Calles públicas. } \\
\text { - Atalayas (cumbre de los cerros Norte y } \\
\text { Suroeste). }\end{array}$ \\
\hline
\end{tabular}

Nota: Fuente: Bueno (1974-75, p. 183).

Laberinto: Se encuentra contiguo al grupo Muelle, por lo que algunos autores como Bueno plantean que se trataría de un solo sector, correspondiendo a dos subsectores (Bueno, 1974-75). La planta general es cuadrangular, conteniendo recintos o espacios internos de planta cuadrangular y rectangulares, las que cumplían diversas funciones. Hacia el norte del sector se aprecia una muralla que define la culminación de la primera etapa constructiva, identificándose otras edificaciones hacia el exterior de esta que corresponde a periodos posteriores, posiblemente áreas de almacenamiento, estrechamente relacionadas con el contiguo recinto este, que Bueno denomina como Kancha este. El acceso a este sector se ubica hacia el lado oriental, mediante dos vanos, uno de ellos comunica el exterior con una gran plaza de planta trapezoidal, mientras que el otro comunica con un recinto rectangular casi al medio del sector. Bueno (1974-75) plantea que el acceso principal se habría ubicado hacia el lado sureste de la plaza principal, no siendo identificado en los trabajos de restauración por lo que hoy no existe. Esta plaza principal abarca un área 
de $2362 \mathrm{~m}^{2}$, conteniendo una banqueta al lado norte de $1.75 \mathrm{~m}$ de alto y $10.65 \mathrm{~m}$ de ancho, a la que se accede por una escalinata de 4 gradas. La función de este sector habría sido ceremonial según las evidencias de la gran plaza, donde se congregaba un número considerable de personas. Desde la plaza, hacia el noreste, se accede a un recinto de grandes dimensiones y planta rectangular, el cual presenta una banqueta de dos niveles adosadas a su muro norte. En la esquina noreste hay un pasadizo al que se accede por una portada de medio punto, comunicándose con el exterior de la muralla, hacia un pequeño recinto rectangular; desde aquí se comunica mediante vanos y pasadizos cortos, con numerosos recintos con banqueta de uno o dos niveles (adosadas por lo general al muro norte), estos se ubican al norte y sur del sector. Algunos de estos recintos presentan hornacinas en los paramentos internos. El llamado recinto 56 (Bueno; 1974-75), es de sección semisubterránea y cercado, con acceso mediante escalinata que desciende hasta su piso, siendo de los pocos casos morfológicos registrados en la Costa Central. La arquitectura general del sector es a base de tapiales, habiendo algunas edificaciones de dos niveles constructivos (a los que se accede mediante escalinatas), así como evidencias de caminos epimurales (figura 04 y 05).

Muelle: Se encuentra al sureste del sector Tello, este sector presenta una pequeña pirámide dominante, con una conglomeración de muros de adobones caídos, hacia el este se encuentra el sector Laberinto, que está asociado directamente (figura 06, 07 y 08).

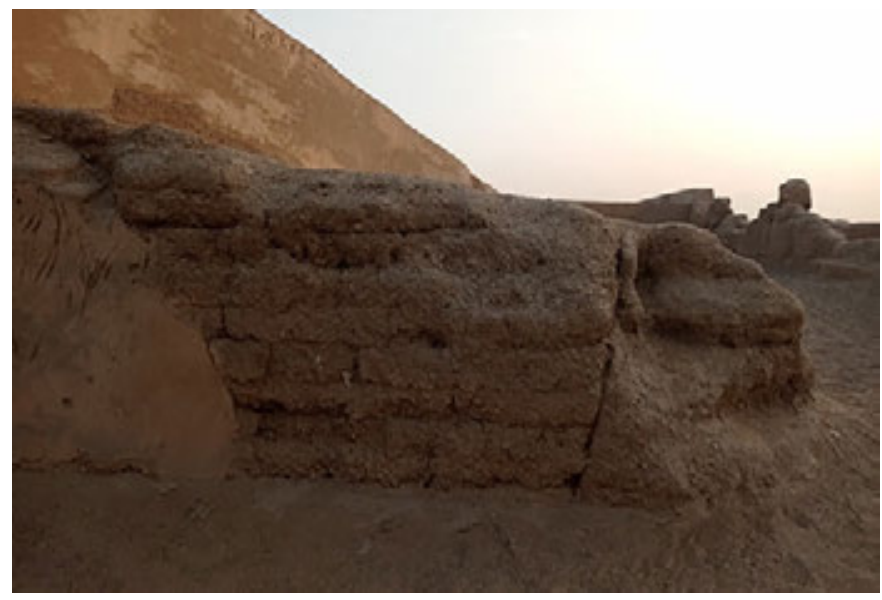

Figura 04. Técnica constructiva de abodes, en muro de sector Laberinto.

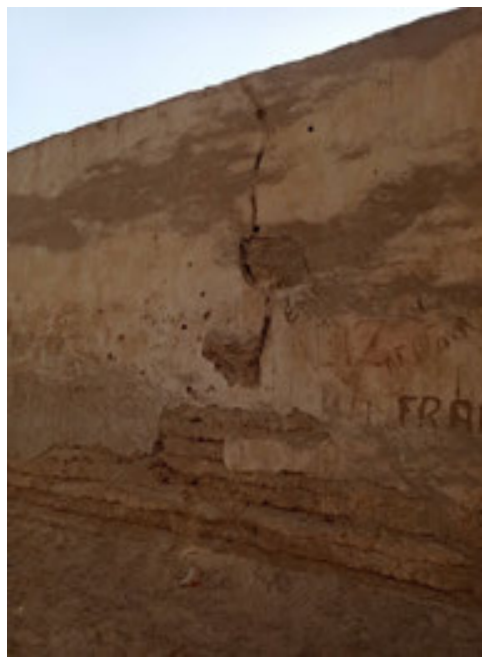

Figura 05. Parte de la restauración del sector Laberinto a cargo de Jiménez Borja. 


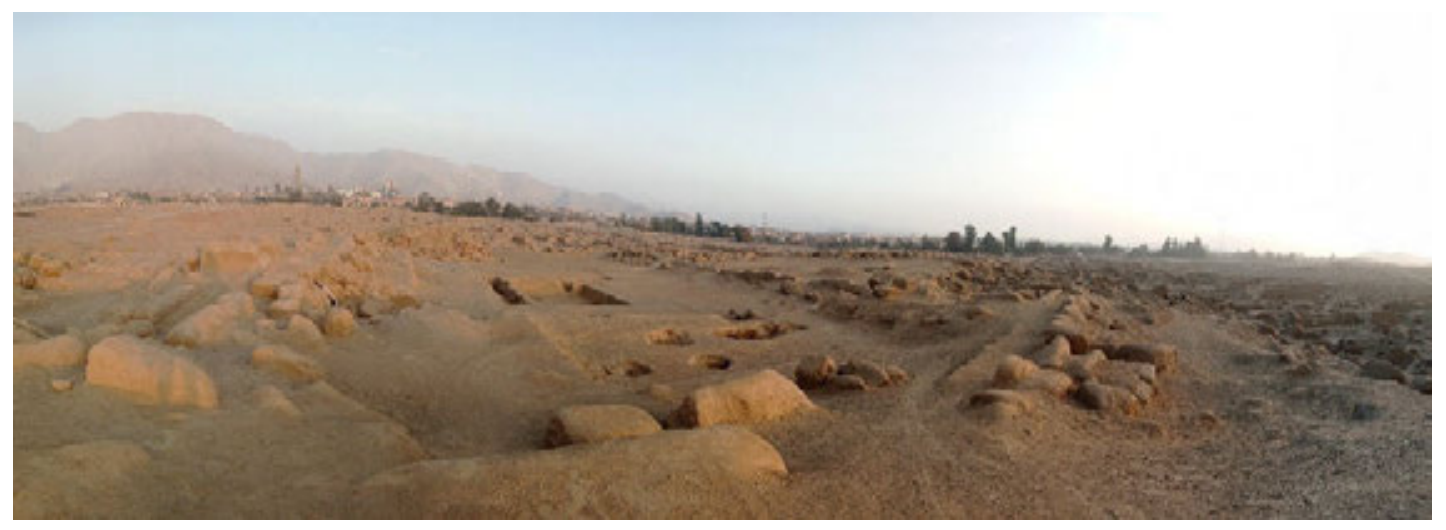

Figura 06. Plataforma superior de la pirámide Muelle.

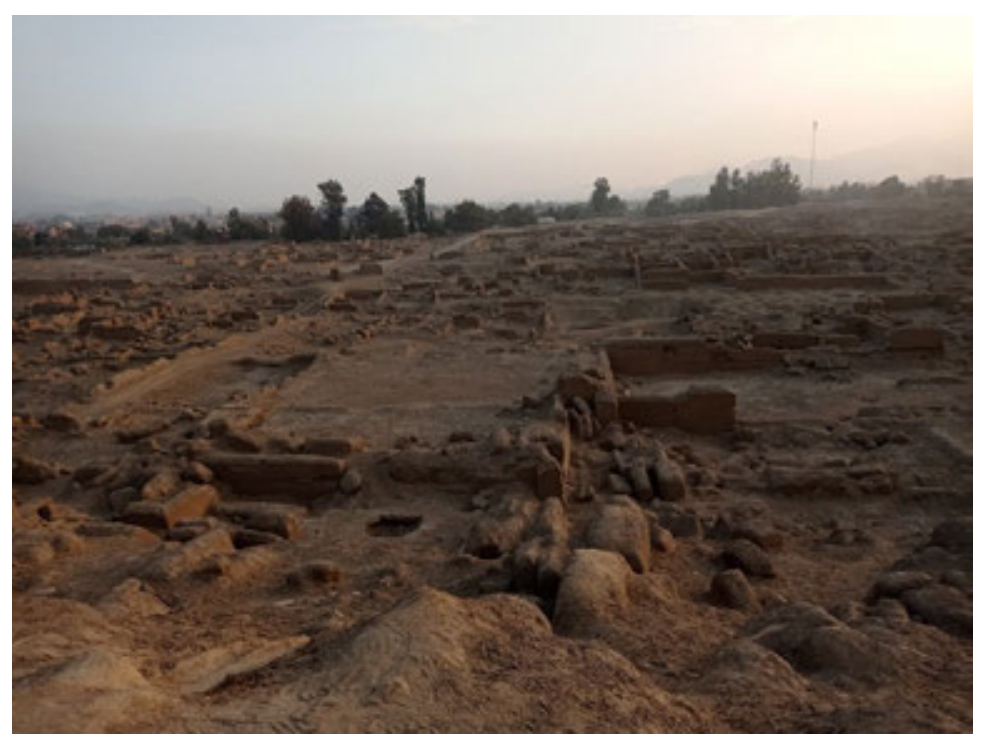

Figura 07. Vista desde la parte superior de la pirámide Muelle, con orientación hacia el Sur.

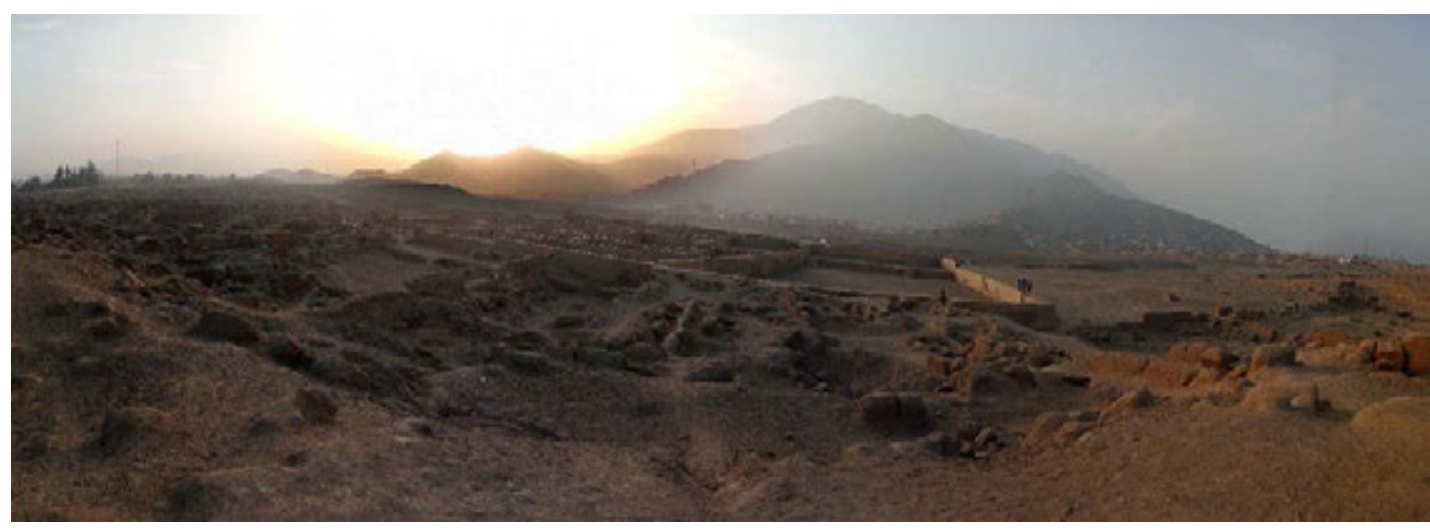

Figura 08. Laberinto, parte asociada al sector Muelle (este-oeste). 
Sestieri: Se encuentra al suroeste del sector Muelle, presenta una pirámide dominante, la parte superior presenta una planta cuadrangular formando por recintos de tamaño regular, hacia el norte y noreste del sector, encontramos muros que delimitan lo que probablemente puede ser plazas o patios, su técnica constructiva está a base de material de abobe y adobones (figuras 09, 10, y 11).

Villar Córdova: Se encuentra al oeste del sitio arqueológico Cajamarquilla, es una de las pirámides dominantes que se encuentra separada de las otras. Esta pirámide posiblemente presenta dos plataformas, en la parte superior se encuentra dividido por un posible pasadizo, al igual que los demás sectores, se encuentra conglomerados por gran cantidad de muros caídos, en el frontis tanto al oeste como

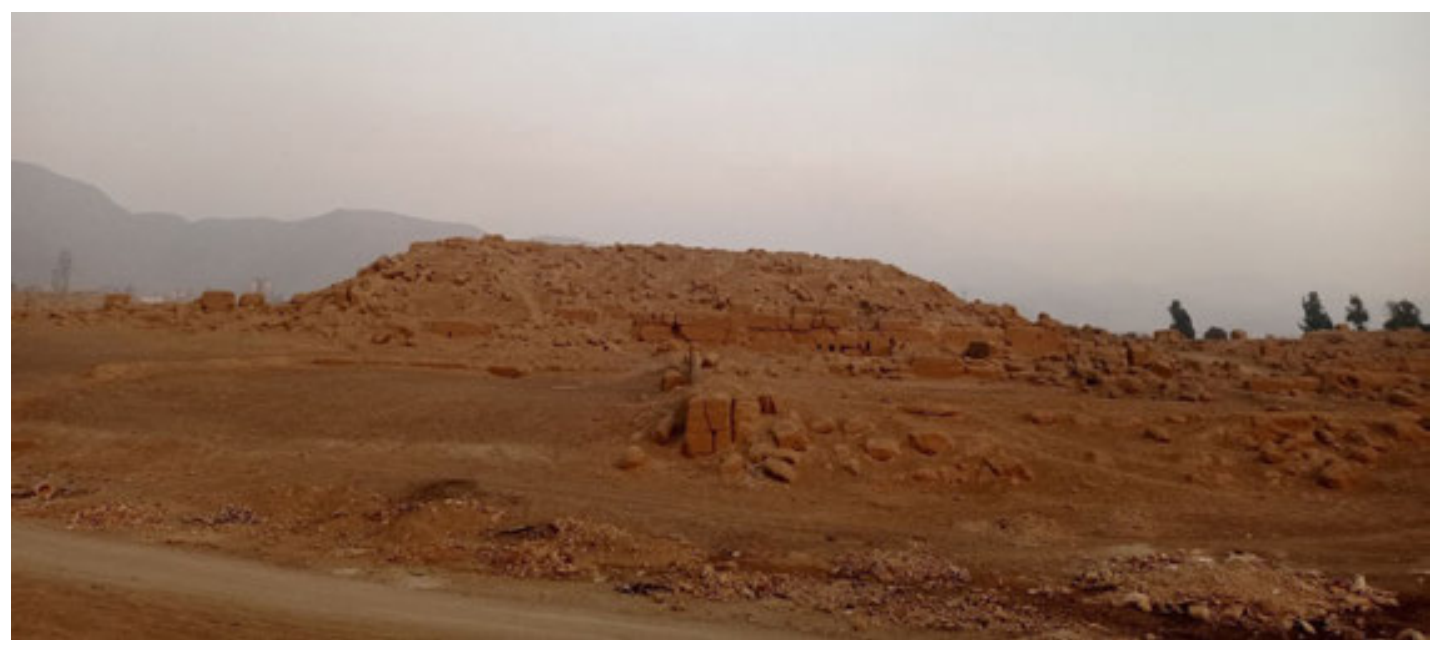

Figura 09. Foto panorámica del sector Sestieri (oeste-este).

Figura 10. Posible frontis de la pirámide Muelle (sur-norte). 


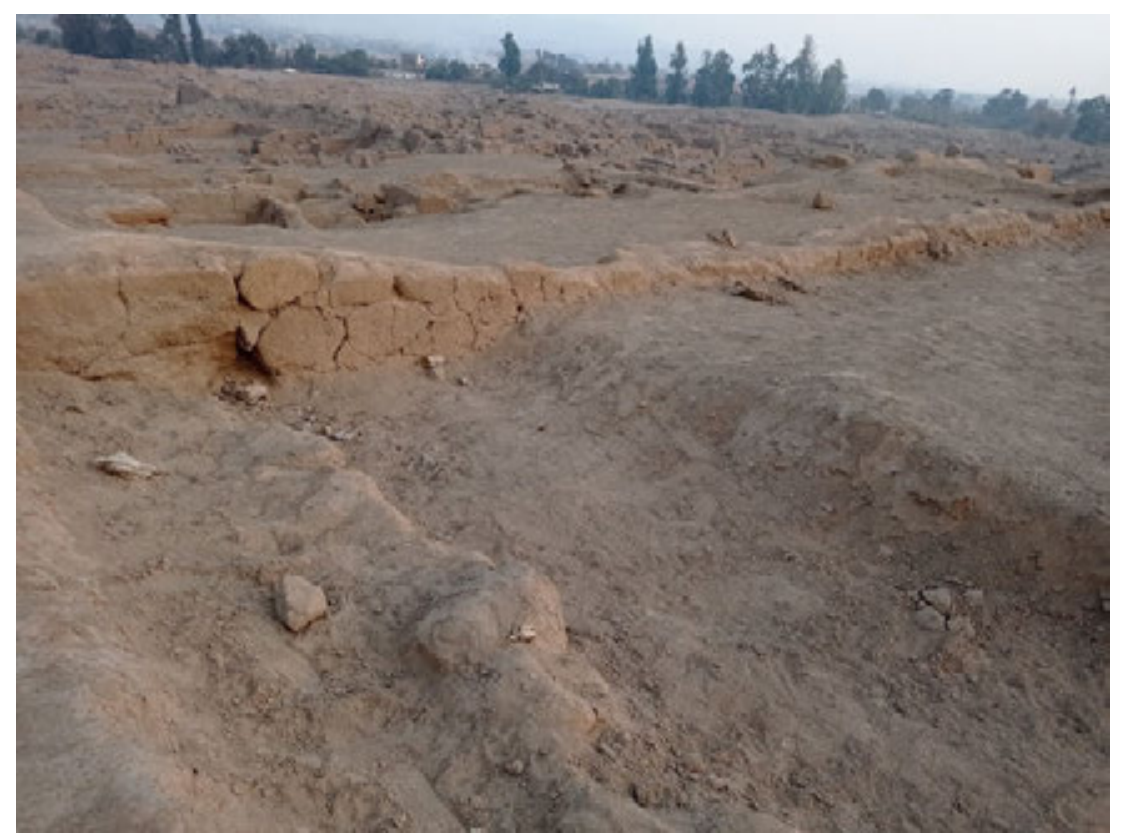

Figura 11. Plataforma superior de la pirámide Sestieri, muro a base de yapana.

al norte, se encuentra plazas o patios delimitados por muros de larga extensión. Alrededor de la pirámide se observa recintos a base de adobes, adobones, yapanas y tapias (figuras 12, 13, y 14).

Tello: Se ubica al noreste de Cajamarquilla, orientada hacia el grupo Muelle, cercado por muros perimétricos de sección trapezoidal, destruido por la esquina suroeste por un huayco. Tiene un área aproximada de $5.928 \mathrm{~m}^{2}$. La descripción detallada de este sector se realizará en los párrafos siguientes (figuras de la 15 a la 20).

\section{LA PROBLEMÁTICA DE LAS OCUPACIONES EN CAJAMARQUILLA}

Los principales problemas que la mayoría de investigadores conocemos o que nos toca vivir, son la destrucción, huaqueo, abandono e invasiones que se da en los sitios prehispánicos de Lima y en todo el Perú; es una realidad que genera una reducción y destrucción a los sitios arqueológicos, disminuyendo la información arqueológica o perdiéndose para siempre. Este es un problema que está aumentado de manera rápida. Por otra parte, los efectos climáticos, como huaycos estacionales, fuertes precipitaciones, fuerte radiación, etc., ocasionan la erosión que también afecta a los sitios arqueológicos. Son una serie de factores, que hacen aún más difícil comprender a estas sociedades prehispánicas, en especial a las que se desarrollaron en el valle del Rímac. 


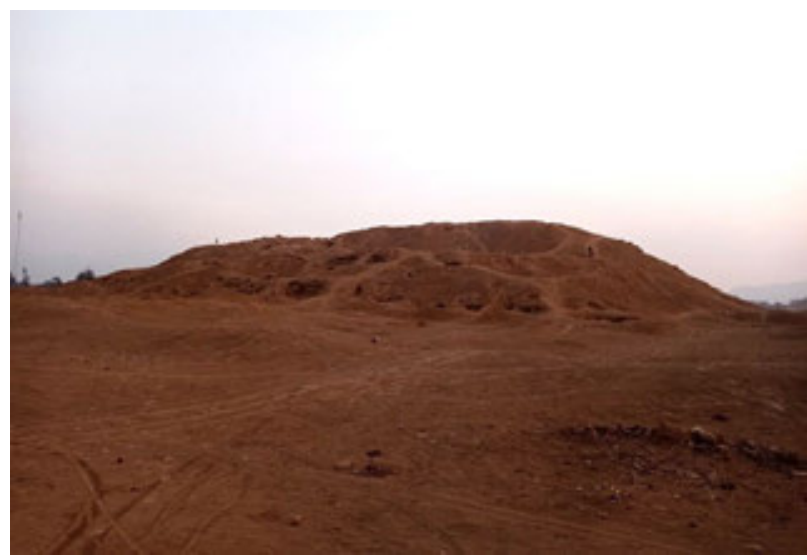

Figura 12. Vista panorámica de la pirámide Villar Córdova.

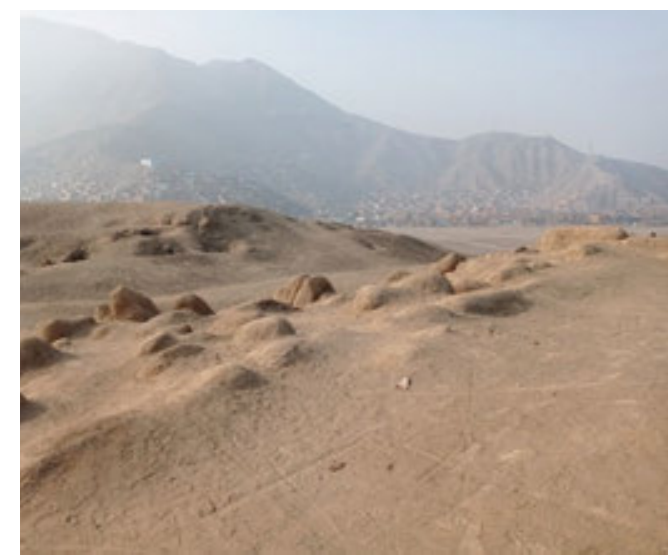

Figura 13. Planta superior de la pirámide Villar Córdova.

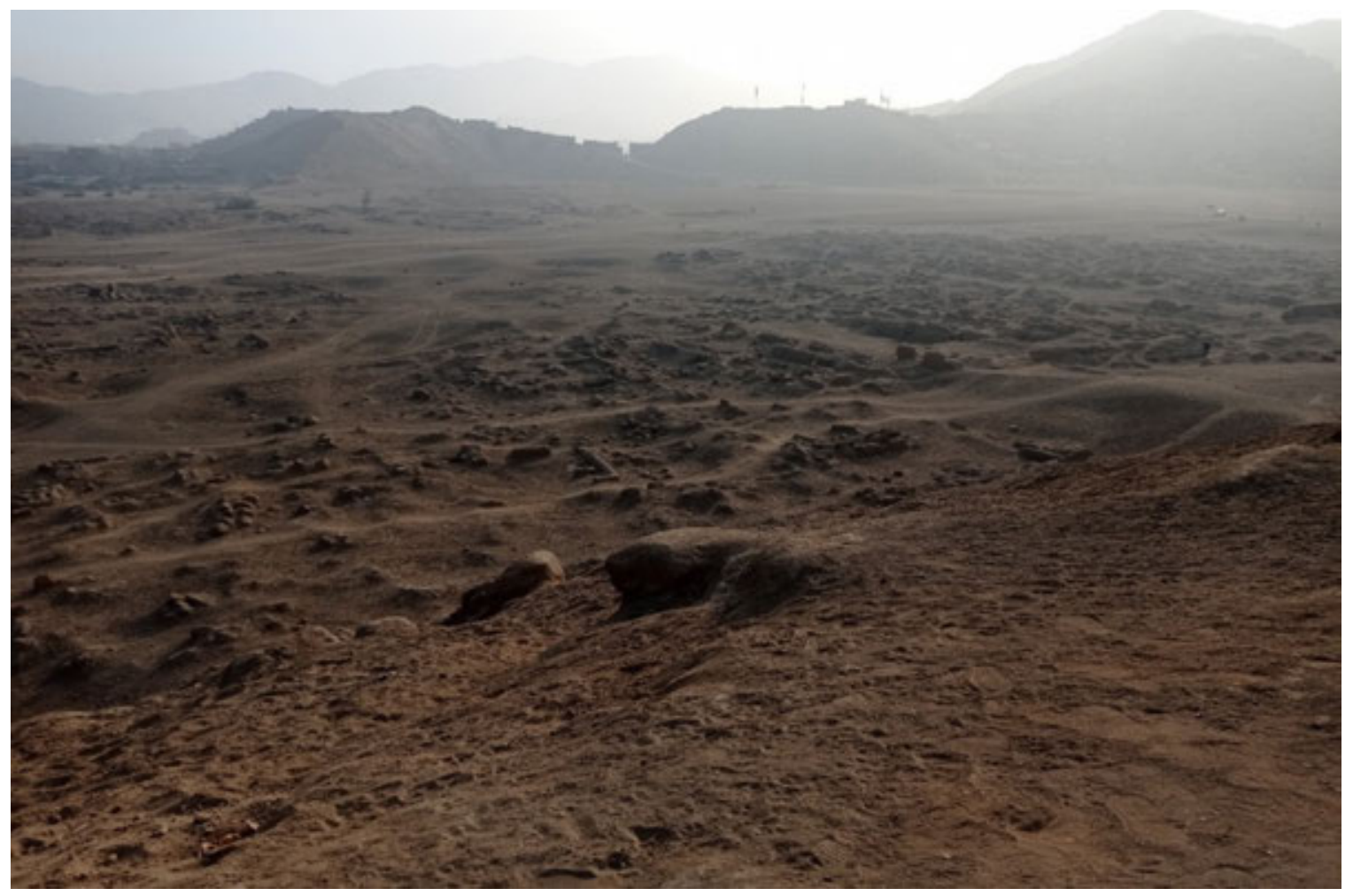

Figura 14. Recintos orientados de note-sur. 


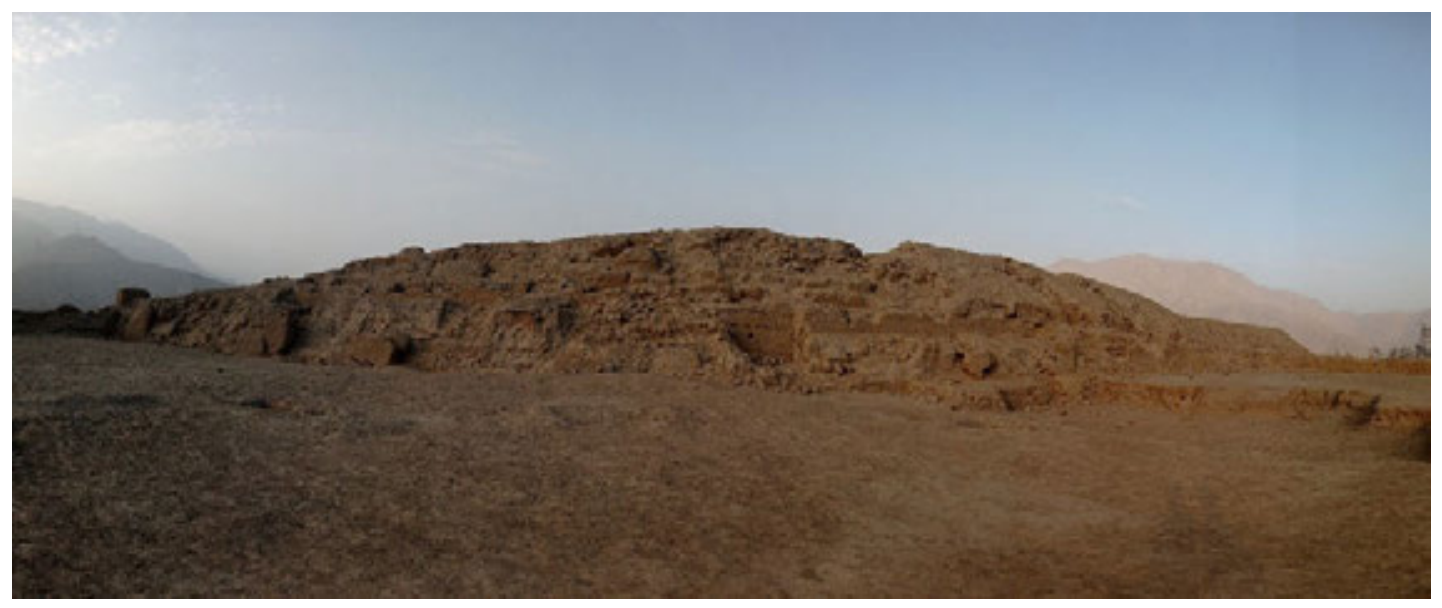

Figura 15. Frontis principal del sector Tello.

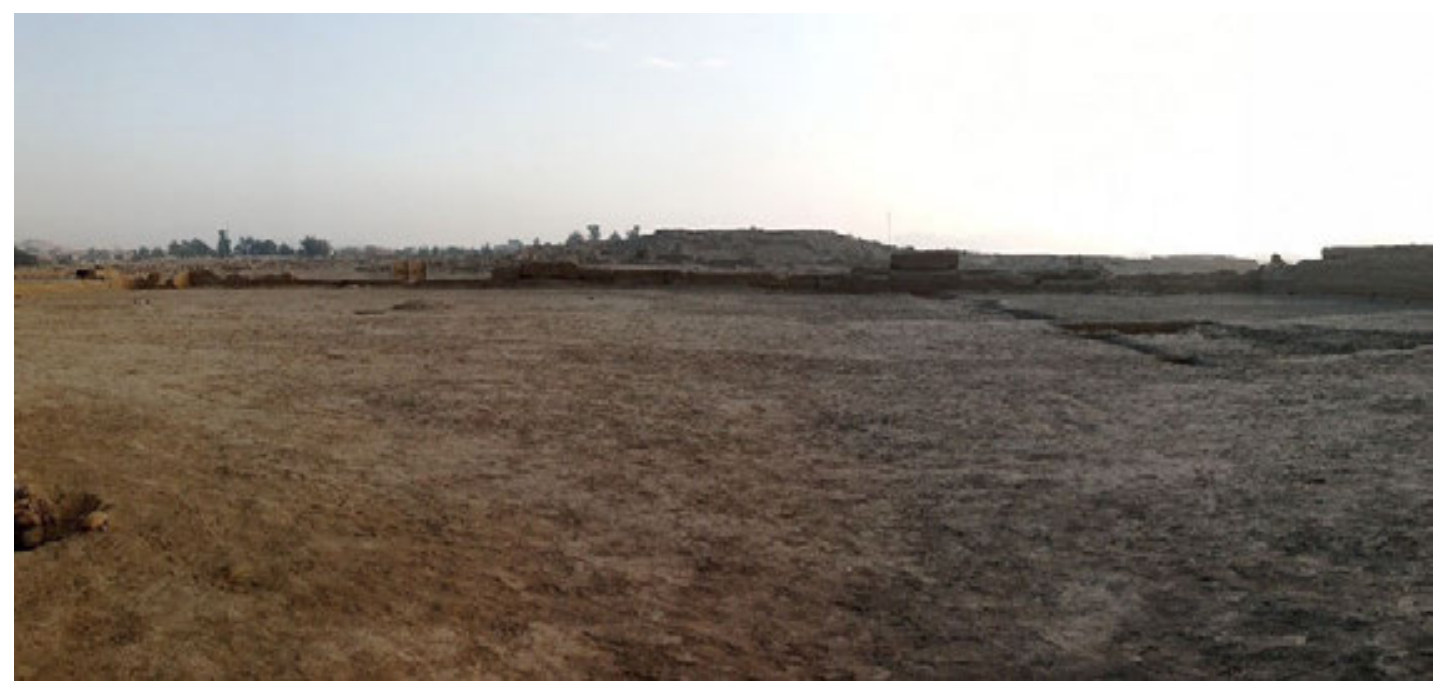

Figura 16. Plaza principal del sector Tello.

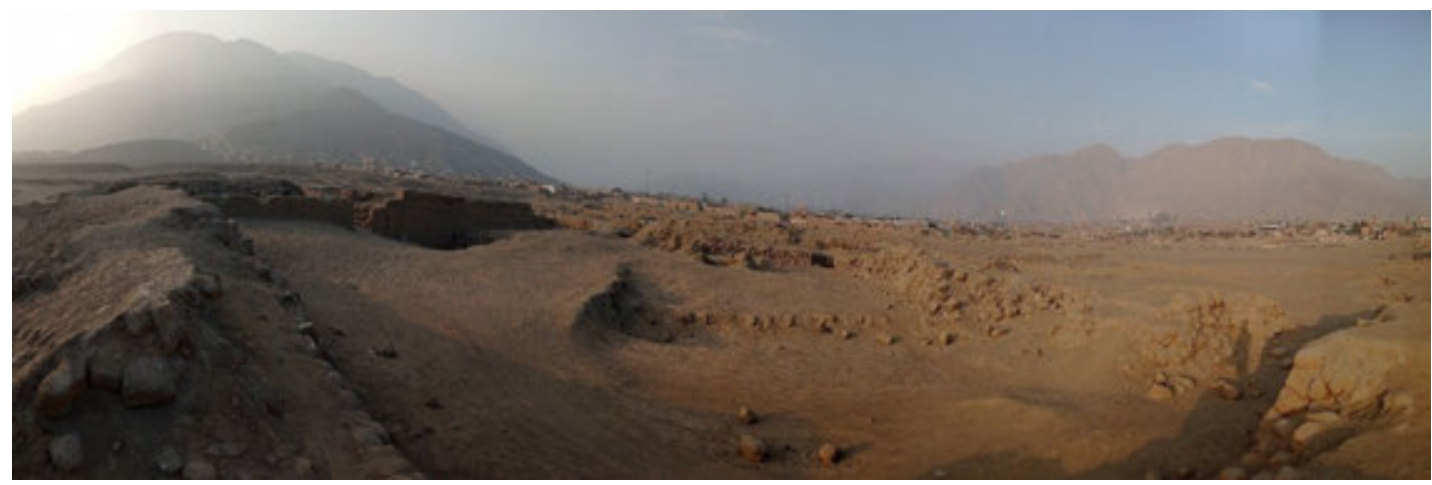

Figura 17. Plataforma superior de la pirámide Tello. 


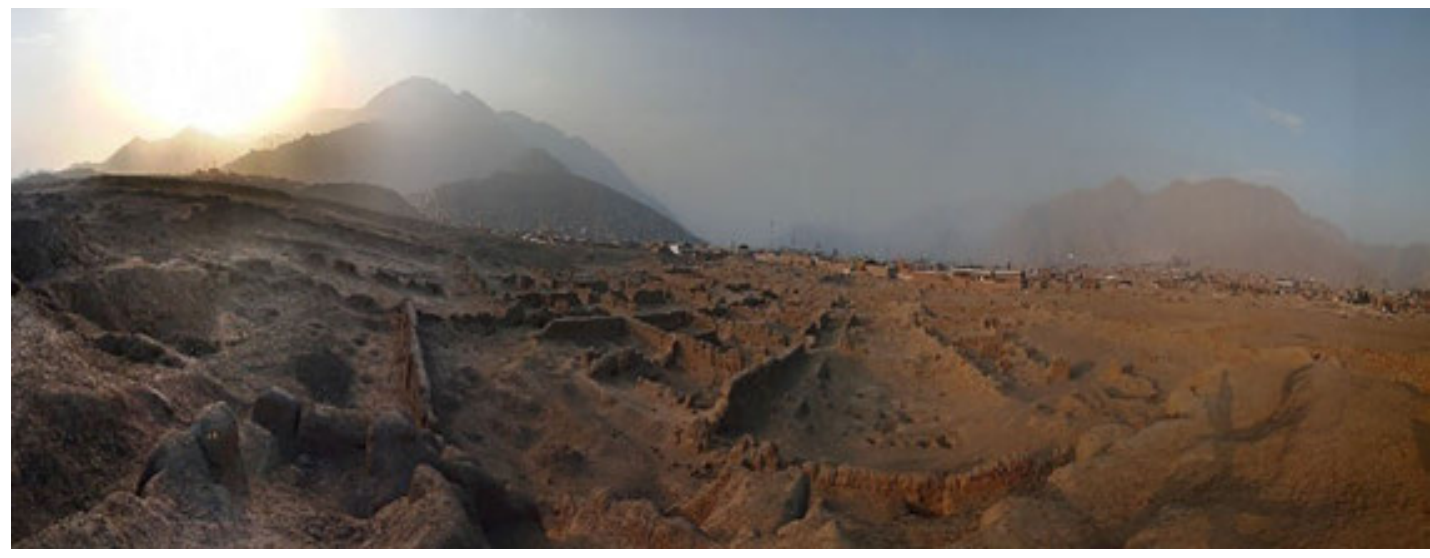

Figura 18. Sector III del sector Tello.

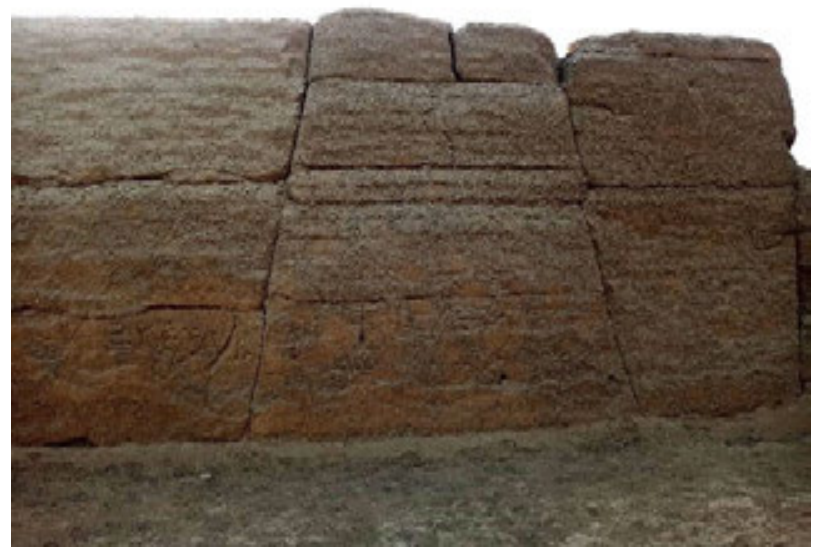

Figura 19. Muro perimétrico de la plaza o patrio principal.

En el caso de Cajamarquilla, se observa a primera vista muchos de los muros derrumbados y en estado caóticos, haciéndose difícil una descripción e interpretación arqueológica completa, situación en la que se encuentra desde el siglo XIX (Squier, 1877). Es por ello que nuestro problema va a tener como punto de investigación el sector Julio C. Tello, que es uno de los sectores que tiene una pirámide dominante, este sector se encuentra más preservado, ordenado y casi nada restaurado (a comparación del sector Laberinto, que fue restaurado en más de 50\%, por Arturo Jiménez Borja en 1980). En relación a las estructuras que se observan en superficie, podemos distinguir el material y las técnicas arquitectónicas, tanto de superficie como los que fueron dejados expuestos por excavaciones pasadas (Mogrovejo, 1997).

Con base en las investigaciones arqueológicas que se realizaron en el sitio de Cajamarquilla (Agurto, 1984; Bueno, 1974-75; Franco, 1998ª 1998b; Lumbreras, 1974, 1981 1998; Menzel, 1968; Ravines, 1989; Sestieri, 1964, 1971; Shady, 1982) se plantea- 


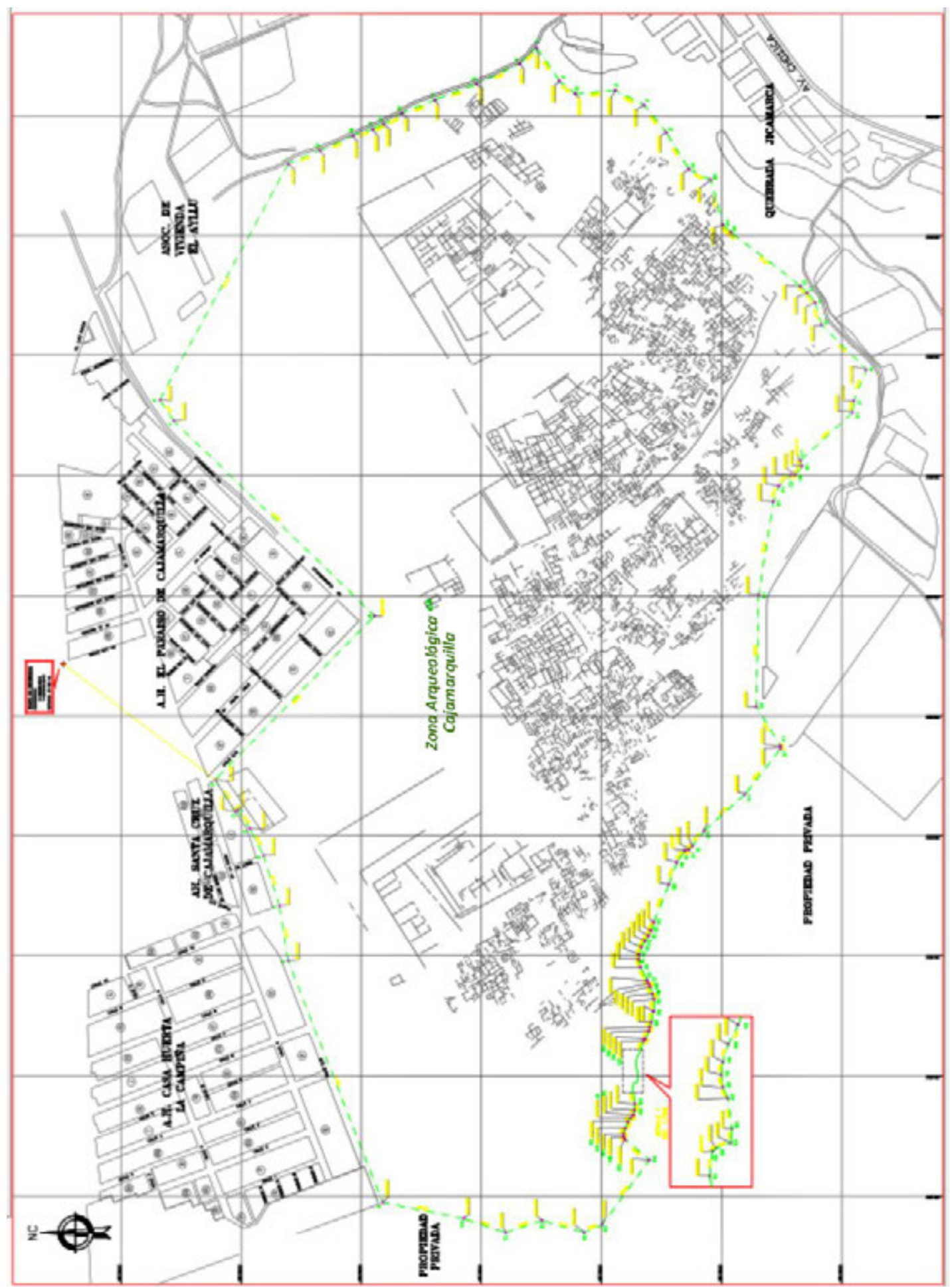

Figura 20. Plano de la Zona arqueológica de Cajamarquilla. Modificado con base en lo publicado por MINCU-COFOPRI (2001). 
ba que el sitio arqueológico de Cajamarquilla tuvo como etapa de mayor importancia y catalogando su acelerado crecimiento (en todo aspecto) en el Horizonte Medio, esta mención estuvo relacionado con la expansión de Huari (Lumbreras, 1988) y quedando en la fase final (Intermedio Tardío), una ocupación simple de campesinos; esto sin tener en cuenta que, para el Periodo Intermedio Tardío los Ychmas tienen una fuerte presencia en el valle del Rímac.

Sin embargo, las investigaciones de las últimas décadas en Cajamarquilla, como el Proyecto Arqueológico de Cajamarquilla, dirigido por Domingo Mogrovejo entre 1996 y 1997, han revelado ocupaciones de otros periodos relacionado al material constructivo, cerámico y textil (Narváez, 2004; Segura, 2001).

La investigación que nos proponemos conducir en este asentamiento, con conocimiento del Museo de Sitio Puruchuco, para cumplir con los requisitos del curso de Prácticas Pre Profesionales II, consistirá en el análisis superficial, externo del sector Tello para determinar sus características: material, forma, dimensiones, organización interna. En consecuencia, el problema principal de esta investigación se orientará a la cronología del sector para aproximarnos al proceso de crecimiento de este complejo arqueológico de Cajamarquilla.

La importancia de este trabajo de investigación, que tiene como base al sector Julio C. Tello del sitio de Cajamarquilla, es tener un concepto bien elaborado de lo que fue este sitio en periodos prehispánicos tardíos, cuál fue su mayor expansión desarrollo o influencia que tuvo; esto en base al estudio de la arquitectura en el Periodo Intermedio Tardío y así aportar científicamente en el campo de la arqueología de la Costa Central, especialmente en el valle de Rímac. Tenemos en cuenta que la mayor información que tenemos acerca de Cajamarquilla son posteriores al proyecto de la Misión Italiana de Sestieri (1962-1971), antes son muy pequeñas las menciones acerca de Cajamarquilla, después de las excavaciones de los italianos a cargo de Sestieri, la mayoría de investigadores coinciden, que Cajamarquilla tuvo un auge o crecimiento en el Horizonte Medio, definiéndolo como centros urbanos, ciudades, emporios comerciales, etc.; pero ya para el año 1997 las investigaciones se intensifican con el Proyecto Arqueológico de Cajamarquilla a cargo de Mogrovejo, cuyos resultados dan una perspectiva diferente a lo que se mencionaba antes, incluyendo la importancia en los periodos Horizonte Medio e Intermedio Tardío, es por ello que en esta investigación se está realizando un estudio detallado y crítico, desde una mirada teórica y metodológica para poder comprender este problema de Cajamarquilla, acerca de su secuencia cronológica, en base al material arquitectónico para el Intermedio Tardío.

El presente trabajo de investigación se enmarca dentro del objetivo número once: "Ciudades y comunidades sostenibles", según el Organismo de Desarrollo Sostenible (ODS) de la ONU, la investigación tiene como objetivo la inclusión del 
patrimonio cultural, en este caso el sitio arqueológico de Cajamarquilla, dentro de las trazas urbanas para el mayor valoración y fortalecimiento de una identidad cultural dentro de la comunidad.

\section{MARCO HISTÓRICO E INVESTIGACIONES PREVIAS}

Las primeras menciones de Cajamarquilla está en los informes del virrey Toledo sobre las reducciones de indios en "Los Reyes". Mr. de Laporte en su libro "El viajero Universal” llamó al sitio Caxamarca la Vieja, ubicándola en el valle que llaman "Guachipa" (Bueno, 1974-75). Otro de los investigadores que investigó este sitio es Julio C. Tello en 1944 (Tello, 1999), por lo cual uno de los sectores lleva su nombre, sus informes se encuentran en el "Archivo Tello" del Museo de Arqueología y Antropología de la UNMSM.

En 1864 Ephrain George Squier hizo una exploración en Cajamarquilla, durante su visita para investigar la arqueología peruana. Squier fue uno de los primeros investigadores que realizó exploraciones arqueológicas en Cajamarquilla, realizando, anotaciones, gráficos y un plano de los sectores Laberinto y Muelle. Sin embargo, él menciona que no logró hacer una datación en Cajamarquilla afirmando solo que "... su historia se pierde incluso para la tradición" (Squier, 1974 [1877], p. 48-52).

Ernst W. Middendorf en su obra: "Perú: observaciones y estudios del país y sus habitantes durante una permanencia de 25 años", en su tomo II, describió varios sitios arqueológicos en Lima comparándolos entre sí, entre ellos describe Cajamarquilla. Al igual que muchos otros investigadores, denota las estructuras formadas por muros con adobes que en ciertos sectores se encuentran en malas condiciones (caídos, desplomados, etc.), resalta las pirámides, dando una función de fortalezas y a los pozos como posibles tumbas o en otros casos como depósitos o almacenes. Estos se encuentran en distintos sectores, en pequeñas plazas o espacios habitacionales como en el sector Tello. Middendorf menciona que esto pudo ser ocasionado por desastres naturales (terremotos). Coincide con esta propuesta Makowski (2001). Middendorf también propuso que la cantidad de habitantes que residieron en el sitio arqueológico, fueron de diez mil a doce mil habitantes aproximadamente, (Middendorf, 1974 [1894], p. 54-55).

En 1905 el arqueólogo norteamericano Max Uhle, hizo trabajos de excavación en Cajamarquilla y en 1906 en Nievería (Ravines, 1989, p. 20-22), las evidencias o materiales arqueológicos encontrados en aquellos sitios, fueron trasladados en el Museo Lowie de la Universidad de Berkeley y estudiados por Ann H. Gayton (1927) y Raoul D'Harcourt (1922), este último, también realizó investigaciones acerca de la cerámica recuperada en ambos sitios, publicando: "La Céramique de Cajamarquilla-Nivería" en 1922, y uno de los sectores en Cajamarquilla actualmente lleva su nombre. Estas evidencias arqueológicas (cerámica) van ser de mucha ayuda para 
Thomas Patterson en 1966 y Dorothy Menzel en 1968; y va a contribuir mucho en la definición de los estilos Lima y Nievería.

Pedro Villar Córdova en su libro: "Culturas prehispánicas del departamento de Lima" (Villar, 1935), menciona en base a la distribución geográfica que, en estos sitios o ciudades de los valles de Lima, el material de construcción no es tan uniforme o no se diferencian mucho. Córdova no tiene una cronología exacta, pero dividió en subtipos los restos arquitectónicos: subtipo 1, este subtipo tiene una similitud con la aldea de pescadores primitivos de litoral, sus construcciones son rústicas y el material son cantos rodados, piedras cortadas, que algunas tienen procedencia de canteras muy cercanas. El subtipo 2, tiene el material de abobes redondos, Villar lo adjunta a las tumbas del valle. El subtipo 3, relacionado con los adobes cúbicos, son pequeños muy similares a los ladrillos, que son encontrados en las colinas artificiales o en las pirámides. El subtipo 4, son construcciones de adobón que forman los tapiales, a base de barro apisonado, este subtipo encaja en Cajamarquilla, que tienen estos tapiales que oscilan entre 0.70 a $1 \mathrm{~m}$ de ancho, que tienen un enlucido grueso de barro, sobre estos espacios que él llama casas, aseverando que estos tenían sus patios o corrales, espacios donde cuidan a sus llamas. Villar realiza una división arquitectónica en: arquitectura militar (Fortaleza de Collique y Atocongo), religioso (Huaca Catalina y Maranka), funerario (necrópolis Ancón y Nievería) y civil, en este último es donde ubica a Cajamarquilla junto a la zona arqueológica de Huaycán. A Cajamarquilla lo ubica en la hacienda Nievería, y menciona que su nombre primitivo es "Lurín-Jicamarca", que significa la ciudad del terreno agrietado.

Alberto Giesecke realizo también investigación en Cajamarquilla, fue encargado por el gobierno peruano de finales de la década de los 30, para restaurar algunos sectores de este sitio y Pachacamac, pero no llegó a publicar sus informes (Ravines, 1989, p. 26).

En 1944 el padre de la arqueología peruana, Julio C. Tello realizó trabajos de excavación en Cajamarquilla (Ravines, 1989, p. 28). Pero los informes originales e inéditos forman parte del "Archivo Tello" que se encuentran en la Casona de la Universidad Nacional Mayor de San Marcos; que consta de 164 páginas, con datos históricos, arqueológicos, fotos y dibujos, el área donde realizó aquella investigación es el sector Tello, quien lleva su nombre, pero el sitio arqueológico en general lo llama "Xika-Marka" (Valcárcel, 1966).

En las investigaciones arqueológicas en la Costa Norte de Richard Schaedel (1951), realiza una clasificación tipológica, de las cuales ciertos autores (Stumer, 1954, Agurto y Pazos, 1982) lo van a aplicar en otras regiones como el valle del Rímac: la arquitectura urbanística; centro ceremonial, centros urbanos de élite, centros-urbanos profanos, centros provinciales de élite y unidades aisladas. A Cajamarquilla la ubican en "centros urbanos de élite", junto a Marcavilca, Huaquerones y Vista Alegre que pertenecen al valle del Rímac. 
Louis Stumer lo describe al complejo arqueológico con una gran extensión, amurallado y que, en la parte interna, como también en las terrazas, tiene una cantidad de divisiones muy complejas, en Cajamarquilla encontraron cerámica en superficie de estilo Tiahuanacoide, Maranga, Inca-Rímac, por lo Stumer propone que hubo una fuerte ocupación continua, a diferencia de otros sitios del mismo valle (Stumer, 1954, p. 238).

Menzel (1968) menciona que en la parte final de la época 2B del Horizonte Medio, el imperio Huari había decaído, a pesar de que era una ciudad importante, en la época 4 fue completamente abandonada:

"No hubo interrupción en la ocupación de Pachacamac, pero los centros más grandes en el valle de Lima, como Cajamarquilla y la parte antigua de la ciudad de Maranga, fueron aparentemente abandonados. El abandono de Cajamarquilla se infiere por el hecho que los últimos entierros registrados en el cementerio de la ciudad de Cajamarquilla datan de la Época 2B" (Menzel, 1968, p. 195).

En la década de 1960 la Misión Italiana dirigida por Sestieri realizaron investigaciones intensivas en varios sectores del sitio de Cajamarquilla (Sestieri, 1964, 1971, 1972). Alberto Bueno (1974-75), en su artículo: “Cajamarquilla y Pachacámac: Dos ciudades de la Costa Central del Perú", identifico en Cajamarquilla tres periodos de ocupación: el primero (Cajamarquilla I) correspondiente a la cultura Lima, cuyos restos conformados por adobitos se ubican en los estratos más profundos del sitio. se basó en los resultados de los fechados de la misión italiana (de la que se desempeñó como codirector), que dató 700 d. C., la cual sería la fecha de ocupación para esta cultura, pero por la similitud con Catalina Huanca, Aramburú y Juliana (Pucllana). Bueno menciona que puede ser más temprano; además que la cerámica Maranga tendría una influencia ayacuchana, por los elementos decorativos (Bueno, 1974-75, p. 182).

Para la segunda fase, Bueno la denomina como Cajamarquilla II, para los siglos X, XI y XII d.C., que está caracterizado con el auge de la cultura Wari, a quienes le atribuye la construcción del sitio arqueológico de Cajamarquilla, por los grandes edificios aglutinados, que internamente forman laberintos.

En el 1300 d. C. Cajamarquilla II, decae, la gente se dispersa motivado por la caída del imperio Huari en Ayacucho, lo que generó la desarticulación social, propiciado por cambios climáticos que a su vez generaron conflictos sociales.

La tercera fase es Cajamarquilla III, Bueno lo caracteriza con la influencia de grupos altoandinos "huanchos" de la sierra de Lima, de "escaso desarrollo cultural" tomando las antiguas propuestas de Villar Córdova, que lo manifestaban en la simplicidad estructural del uso de la yapana, asociadas a las últimas ocupaciones del sitio, quienes, según Bueno, serían los huanchos (Ibid). 
Cuadro 2. Ocupaciones culturales de Cajamarquilla según Bueno (1974-75).

\begin{tabular}{|c|c|c|c|}
\hline Tiempo Relativo & Periodos Nacionales & Cajamarquilla & Pachacamac \\
\hline 1440 - 1533 NE. & Tawantinsuyo & Huanchos & IV Tawantisuyo \\
\hline $1200-1440 \mathrm{NE}$ & Reinos y Confederaciones & III Huancho & III Rma o Ishma \\
\hline $800-1200 \mathrm{NE}$. & Wari & II Wari & II Wari \\
\hline $100-700 \mathrm{NE}$. & Formaciones Regionales & I Maranga & I Maranga \\
\hline 1800 - 100 ANE. & $\begin{array}{l}\text { Superior } \\
1200 \text { - } 100 \text { ANE. } \\
\text { Inferior } \\
1800 \text { - } 1200 \text { ANE. }\end{array}$ & $?$ & $\begin{array}{l}\text { Cerámica Chavín de } \\
\text { la Tablada y el Valle. } \\
\text { Cerámica inicial de } \\
\text { Tablada de Lurín }\end{array}$ \\
\hline $3500-1800$ ANE & Precerámico & $?$ & $\begin{array}{l}\text { Conchales en Tabla } \\
\text { de Lurín Lomo de } \\
\text { Corvina/Conchan }\end{array}$ \\
\hline 1800 - 600 ANE. & $\begin{array}{l}\text { Reciente } \\
6000 \text { - } 3500 \text { ANE. } \\
\text { Primordial } \\
1800 \text { - } 600 \text { ANE. }\end{array}$ & & \\
\hline
\end{tabular}

Luis G. Lumbreras (1974), plantea que Cajamarquilla se constituyó en un centro administrativo del imperio Wari (p. 155) evidencia de una intensiva aglutinación poblacional en torno a los centros públicos de servicio y producción (Lumbreras, 1981, p. 171).

Ruth Shady publica en 1982: "La Cultura Nievería y la interacción social en el mundo andino en la época Huari", señala que desde finales del Intermedio Temprano (350-450 d. C.), por lo menos en su fase 7 las poblaciones del valle del Rímac logran tener mayor poder y prestigio similar y paralelo al que van a tener todavía las poblaciones Lima que aún van a seguir ocupando los antiguos espacios públicos y ceremoniales en el interior del valle, como Cajamarquilla, Huaca Trujillo, Vista Alegre, Mangomarca y Huaca Pucllana (Shady, 1982, p. 13-14). Shady señala también que Cajamarquilla constituye una ciudad donde se va asentar el poder económico y político del Rímac en las épocas 1 y 2 del Horizonte Medio; con presencia de una elite religiosa, personal, burocrático administrativo, curacas, artesanos quienes van a dominar directamente a las clases populares, dedicados a la agricultura principalmente. 
Shady, afirma también la importancia estratégica de Cajamarquilla, encargada de la acumulación del excedente intercambiable que procedía de los pueblos de la sierra de Lima y de la sierra central (ibíd., p. 60). Estas actividades denotan la presencia de un personal jerárquico especializado a dedicación exclusiva, encargada de regular las diversas actividades laborales artesanales, como la elaboración de artefactos con materias primas traídas de lugares lejanos. Shady propone que la existencia de abundante silos y graneros eran para almacenar productos destinados a la actividad comercial, planteando la existencia de un gran emporio comercial en Cajamarquilla; donde en paralelo se desarrollaban actividades religiosas, administrativas, sociales, comerciales y políticas. En este contexto se construyeron grandes sectores con pirámides residenciales y áreas comerciales, articuladas mediante calles y plazas. Para la época 2B la importancia de Cajamarquilla fue reemplazado por Pachacámac (Ibíd).

Santiago Agurto (1984) en su obra: "Lima Prehispánica", señaló que durante la expansión Wari, se establecieron centros administrativos en lugares estratégicos de su extensión territorial, encargados de la administración provincial y de cumplir los mecanismos establecidos por la capital Wari en Ayacucho. Uno de estos centros urbanos fue Cajamarquilla encargado de controlar y mediar la dominación Wari en la sociedad Lima, no tuvo sin embargo una imposición muy rigurosa en la primera época (500-700 d. C.) mientras que en la segunda (700-1000 d. C.) el largo trato con sus pobladores habría determinado en los conquistadores un ánimo más benigno que en otras regiones (p. 104-105).

Entre 1996 y 1997 el proyecto arqueológico de Cajamarquilla, estuvo a cargo del arqueólogo Juan Mogrovejo, quien realizó intervenciones en el sector Tello; sin embargo, muchos de los datos recuperados aún permanecen inéditos; participaron en el proyecto los arqueólogos Rafael Segura, Joaquín Narváez y Makowski.

Cabe destacar las investigaciones con excavaciones dirigidas en varias temporadas $(1998,1999)$ del arqueólogo Dante Casareto, intervenciones de mayor envergadura de las últimas décadas en el sitio, en las cuales se realizaron excavaciones en grandes áreas de los sectores Tello y Muelle; resultados que lamentablemente hasta el momento no han sido publicados y solo se puede consultar los informes (Casareto, 1999, 2000).

Mogrovejo y Makowski (1999) señala que periodos de intensas lluvias en la sierra central habrían activado la quebrada Jicamarca, generándose un caudal permanente en ciertas épocas del año; situación que contribuyó en brindar la materia prima para la construcción de grandes edificaciones de tapiales. Esta situación provocó la construcción de reservorios y canales secundarias, habilitándose bocatomas, que alimentaban a los canales troncales, estos se ubicaban al oeste de Cajamarquilla, muy cerca del sector Tello. Edificaciones de grandes dimensiones que rodeaban perimétricamente los sectores que se encontraban continuos a los reservorios que abastecían de agua a la ciudad. 
Mogrovejo y Segura (2000) proponen una secuencia constructiva y de usos en el sector Tello: la primera fase A y B formado por pisos y recintos en el Sector I. En la fase C, esta subdivida en 4 sub fases, CI se inicia con la construcción de la pirámide, y culmina con actividades rituales y ofrendatorias de roturas de vasijas, clausurando esta pirámide para la construcción de otra pirámide de mayor espacio (fase CII), cuya cima se habilita un enorme patio circundado por muros de tapias con 4 vanos, siendo el principal al lado este, al que se accedía a través de una gran rampa desde recintos pequeños. La tercera subfase CIII, consiste en el relleno de este patio y la construcción de muros de yapana unidad con argamasa y enlucido de blanco. En esta sub fase CIII, casi todos los espacios están abandonados; corresponde a la sub fase CIV, una ocupación de pastores que emplazan chozas circulares en la base de la piramide y encierran su ganado en la cima. Un fuerte sismo posterior hizo colapsar muchos muros provocando el hundimiento de piso. Posteriormente fue utilizada por área funeraria hasta finales del Horizonte Medio II, para ser reocupado con pequeñas remodelaciones en el Periodo Intermedio Tardío (fase D).

Cabe señalar también la propuesta recién publicada de gestión cultural para el sitio de Cajamarquilla, en la cual analiza las potencialidades que tiene el sitio arqueológico para su puesta en uso social y su habilitación de recepción para la sociedad (Cáceres, 2021).

En las investigaciones en el valle del Rímac, tras la caída de la influencia Chavín se desarrollaron sociedades complejas que se sustentaban económicamente en la agricultura intensiva, la ganadería y la explotación intensa de recursos marinos por medio de la pesca y aprovechamiento continuo de recolección de mariscos. Hay una cantidad de investigadores que mencionan que las sociedades de la Costa Central que son posteriores al Horizonte Medio como Lima, Nievería e Ychsma, desarrollaron un modo de vida urbano y organización política estatal. Makowski (2001) menciona que en las épocas finales del Intermedio Temprano en la Costa Central se da el complejo patrón de asentamiento con arquitectura monumental entre áreas ceremoniales y estructuras de aspecto de palacios la cual se debería probablemente al surgimiento de una organización estatal (p. 170).

Como escribe Narvaez (2004), el sitio arqueológico de Cajamarquilla ha sido calificado como un asentamiento de tipo urbano por varios autores, por ejemplo shady (1982) lo definió como un centro urbano multifuncional donde se realizaban varios aspectos de la vida social (religiosas, comerciales, políticas, administrativas, etc.). Stumer (1954) lo denominó "centro urbano de élite", Menzel (1968) "ciudad", Lumbreras (1974) "ciudadela”. En cambio para Bueno (1974-75), como apunta Narvaez, Cajamarquilla no habría sido una ciudad construida para vivir cotidianamente pues no se encontraron basurales o cementerios.

Con respecto a las investigaciones del arqueólogo Joaquín Narváez (2004), menciona la presencia de espacio públicos, tanto en el periodo de arquitectura monu- 
mental como arquitectura más modesta, desarrollándose actividades religiosas, artesanales, habitaciones y de congregación social; para la ocupación Ichma, evidencia grandes edificios que se ajusta a la idea de un "gran centro urbano" en donde vivían grupos de poder que realizaban actividades ceremoniales y administrativas, alentadas por artesanos dedicados a la elaboración de distintos productos, en especial de textiles y cerámicas. Este complejo arqueológico abarcaba y concentraba gran parte de la producción local para su consumo y distribución (Narváez, 2004).

Narváez (2004) para el sitio de Cajamarquilla identifica el material constructivo en relación a su secuencia cronológica, esta primera fase sería del Intermedio Temprano, con la presencia de los adobitos también están los tapiales, relacionado a la cultura Lima; en cambio en la segunda fase se descarta la presencia Wari por falta de evidencias; y en la última fase, y donde le damos más importancia, es al Intermedio Tardío que presenta una gran complejidad y en la cual se da la máxima extensión de las edificaciones amuralladas de tapiales en el sitio, en especial en el sector Tello relacionado a la cultura Ichma, lo cual es propio del valle del Rímac.

Cuadro 3: Secuencia estratigráfica, constructiva y ocupacional del sector Julio C. Tello.

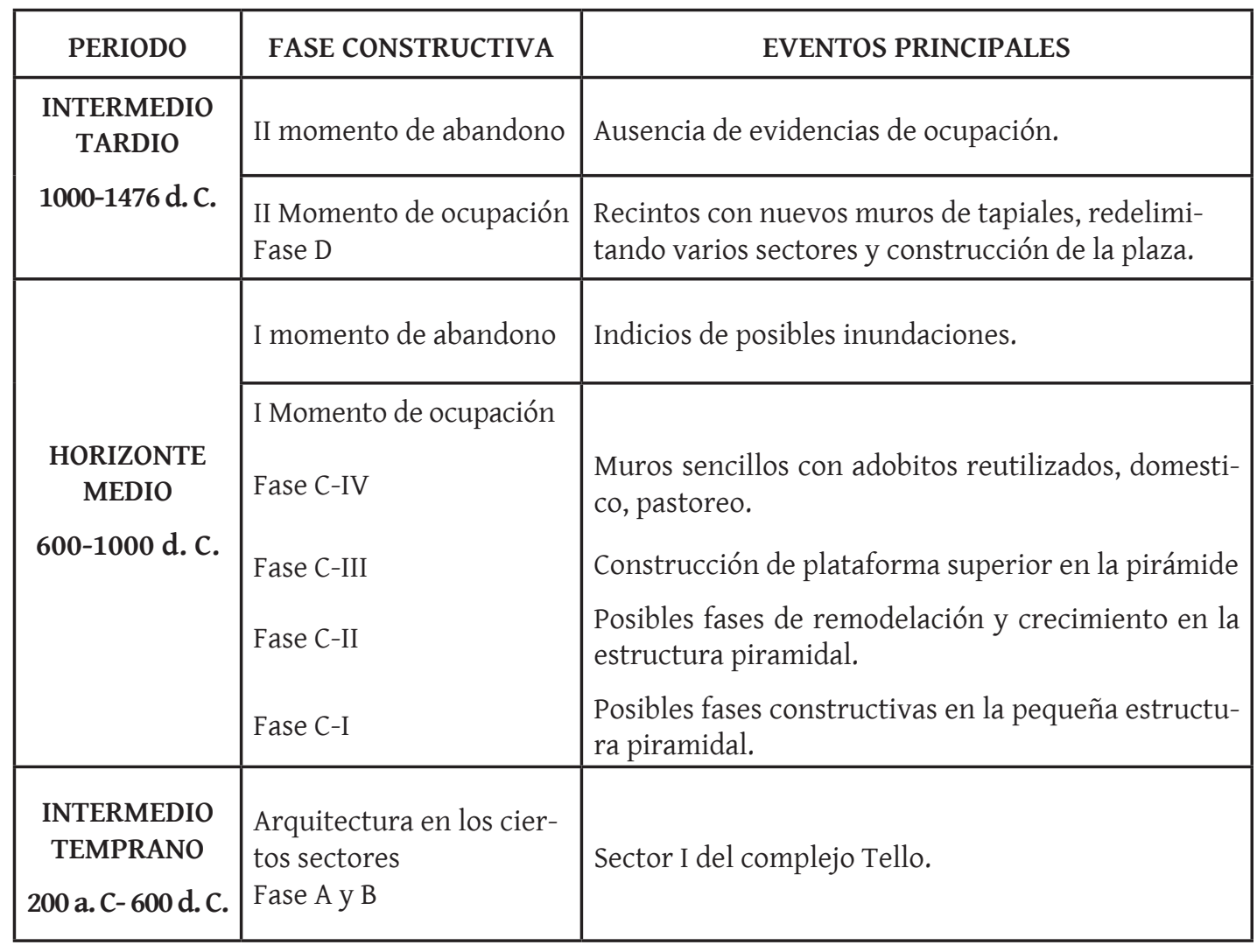

Nota. Fuente: (Mogrovejo y Segura, 2000, p. 567). Boletín de Arqueología PUCP, No 4, 2000. 


\section{EL PERIODO INTERMEDIO TARDÍO EN EL SECTOR TELLO DE CAJAMARQUILLA}

\section{1.- El Periodo Intermedio Tardío en el valle medio inferior del Rímac}

El Periodo Intermedio Tardío es el periodo cultural de la secuencia prehispánica andina, definido por John H. Rowe (1946), inmediatamente anterior a la expansión Inca por todos los Andes. Sus inicios fueron calculados hacia el año 1100 d. C., mientras su finalización depende del momento en que las diversas sociedades andinas fueron sometidas por el expansivo estado cusqueño (mientras que en regiones cercanas al Cusco este proceso se dio hacia el año 1430 d.C., en el actual Ecuador se dio hacia 1500 d.C). Este periodo se caracteriza por el desarrollo de múltiples sociedades a lo largo y ancho de todo el Ande (costa, región alto andina y ceja de selva). En el caso de la costa las formaciones sociopolíticas de este periodo se desarrollaron en dos o más valles contiguos, siendo Chimú la sociedad que ocupó una mayor extensión territorial al momento de su máxima expansión (entre Tumbes y el valle de Fortaleza o Paramonga). En la costa central, sociedades como Chancay, Ishma y Guarco ocuparon hasta tres valles contiguos. En la región altoandina, las diversas sociedades de este periodo ocuparon menores extensiones territoriales que en la Costa, abarcando una o dos cuencas, o incluso solo una subcuenca (van Dalen, 2013); este es el caso de la sierra de Lima, donde encontramos en el Periodo Intermedio Tardío a diversas formaciones sociopolíticas, como en el caso de la actual provincia de Huarochirí donde encontramos a los checas, quintis, huarochiris, tupicochas, castas, chacllas, entre otros (van Dalen, 2014).

En muchas de estas sociedades las manifestaciones culturales son similares. Los asentamientos en la región altoandina están conformados por edificaciones de planta ovalada o rectangular, con muros edificados a base de piedras canteadas unidas con argamasa, emplazados casi siempre en la cima de los cerros más altos; en el caso de la costa, los asentamientos tienen por ubicarse en los rincones de los valles, sobre extensas pampas o terrazas aluviales, con edificaciones de planta cuadrangular, de muros hechos con tapiales y adobes (barro). En cuanto a la cerámica, no es tan elaborada como en periodos anteriores, en la costa es moldeada con pintura post cocción, predominando los estilos Negro sobre Blanco; mientras que en la región altoandina predomina la cerámica modelada, con decoración escultórica.

Rostworowski (2018) señala que en el caso de la Costa las sociedades eran altamente jerarquizadas, con una división social entre agricultores, pescadores, artesanos, entre otros. Estas sociedades estaban organizadas en ayllus, cada uno de los cuales tenía un territorio definido en el cual desarrollaron sus actividades económicas.

El Periodo Intermedio Tardío, en general, se caracteriza por tener un primer momento (1100-1250 d. C) en el que se desarrolló un pequeño repunte glaciar, produciéndose un descenso en la temperatura, disminuyéndose las áreas productivas, situación que produjo constantes conflictos interétnicos, en especial en la región 
altoandina. Por ellos la ubicación de los asentamientos altoandinos en lugares estratégicos, de difícil acceso, rodeado por sistemas de murallas y con sitios estratégicos de vigilancia. Hacia 1250 d. C., se retoma el óptimun climáticum produciéndose una expansión de las áreas productivas.

El área donde se encuentra ubicado Cajamarquilla es una quebrada afluente del valle medio inferior del Rímac. Sobre las sociedades que ocuparon este territorio en el Periodo Intermedio Tardío, existen varias propuestas, siendo la más antigua la de los huanchos, planteada por Villar Córdova (1935), quien lo define como un grupo que invadió el valle de Lima desde el Horizonte Medio, que habrían descendido de la sierra de Lima a través de las quebradas laterales del Rímac, para establecer sus poblados, primero en estas quebradas y luego en los rincones del valle mismo. Louis Stumer define que la cerámica Huancho se caracteriza por ser de pasta marrón o rojiza, gruesa, con decoración pintada (líneas blancas), en contraposición a Villar (1935) quien señalo que era polícroma y escultórica (Bazán, 1992, p. 5). Otros autores como Iriarte (1960), Bonavía (1965) y Ludeña (1975) continuaron con la definición de la sociedad huancho en los valles de Lima.

Años más tarde, Francisco Bazán del Campo (1990) define la sociedad Ichma a partir de las fuentes etnohistóricas y la seriación de cerámica, la cual habría ocupado los valles de Lima en periodos prehispánicos tardíos. Es así como en las últimas tres décadas, numerosos autores han investigado sitios y contextos arqueológicos Ichma en este territorio (van Dalen, 2012a).

Luisa Díaz (2008) plantea que el territorio Ichma abarcó los valles bajos de los ríos Lurín, Rímac y Mala; citando a Narváez para señalar que Cajamarquilla tiene ocupación Ichma Medio, con:

“.... Una parte del material cerámico identificado corresponde a un tipo de cántaros de cuerpo compuesto, que ha sido llamado estilo Cuculí. (....) Respecto a este material Guerrero (2004: 172) siguiendo a Engel, afirma que se trata de una tradición cerámica que viene de la sierra de Lima y que coexiste con el estilo cerámico Ichma en los valles bajos de la costa central, marcando una frontera entre los estilos serranos y costeños. Para el, este estilo está reflejando la expansión de las poblaciones serranas hacia los valles medios de la cota y su presencia en los valles bajos es producto del intercambio." (Díaz, 2008, p. 120-121).

Para la quebrada de Lurigancho, Julio Abanto (2008) señala que en el Periodo Intermedio Tardío estuvo ocupado por el señorío de Rurincancho, una parcialidad de los Ichma, siendo Mangomarca su sede política, donde se ha identificado cerámica de estilo Ichma. Abanto identificó vías de comunicación entre la quebrada de Lurigancho (Canto Grande) y la de Jicamarca, que le permitió relacionar los sitios de Cajamarquilla y Mangomarca; señalando que en el primero se establecieron los Ichmas. 
Más adelante señala que los Jicamarca fueron:

“.... Una etnia Yauyo, pastores de camélidos; que se asentaron, durante el Intermedio tardío, en las alturas del valle de Santa Eulalia, y acompañada de otras etnias, como los Chacllas y Carampoma, se lanzaron a la conquista de la margen derecha del Rímac, llegando hasta la zona de Huachipa...." (Abanto, 2008, p. 168).

Para la zona de Carapongo del valle de Rímac, Lida Casas (2017), plantea a partir de sus investigaciones en los sitios arqueológicos Carapongo B y Caraponguillo, que durante el Periodo Intermedio Tardío, esta zona estuvo ocupado por los Ishmas, quienes dieron una importancia económica a esta zona mediante la construcción de canales de irrigación a fin de ampliar la frontera agrícola. Para el Horizonte Tardío, el Tawantisuyo introdujo en los alrededores a mitqmas chacllas a fin de controlar a los grupos locales (Dolorier; 2017). Esta situación está relacionada con las ocupaciones serranas de toda esta sección del valle medio del Rímac, como lo señalan los manuscritos quechuas de Huarochirí (Taylor; 1987), que narran como los huarochiranos dirigidos por Tutayquiri conquistaron y dominaron todo el valle medio del Rímac hasta Lati (Ate).

\section{2.- El Periodo Intermedio Tardío en Cajamarquilla}

La mayoría de investigadores han resaltado la ocupación del Horizonte Medio en Cajamarquilla, asegurando incluso que su máxima expansión se dio en este periodo, asociándolo con la expansión Wari. Sin embargo, creemos que la mayor expansión de este sitio monumental con planificación urbanística se dio en el periodo posterior, tal como lo están afirmando algunos investigadores en los últimos años.

José Canziani afirma que la mayoría de edificaciones visibles en Cajamarquilla corresponden al Periodo Intermedio Tardío, las cuales se superponen a edificaciones de la cultura Lima:

"En el caso de Cajamarquilla, las investigaciones arqueológicas en esta ciudad dominada por las construcciones del Intermedio Tardío han reportado la abundante presencia de materiales culturales del periodo Lima, al igual que distintas evidencias de estructuras de esta época con los típicos adobitos bajo las estructuras tardías (Tello; 1999)." (Canziani, 2009, p. 272).

A continuación, presentamos las características del sector Tello de Cajamarquilla, con mayor énfasis en la arquitectura del Periodo del Intermedio Tardío.

\section{3.- El sector Tello}

La investigación en campo del sitio arqueológico de Cajamarquilla, ha incidido en el sector o conjunto Julio C. Tello, que lo dividimos según su distribución y configuración espacial en 5 subsectores. Se ha podido realizar un registro fotográfico, 
levantamiento, mediciones y reconocimiento del material constructivo, en todos los subsectores, logrando realizar los planos de distribución, construcción arquitectónica, y a partir de esta información realizada en campo se ha contrastado las características arquitectónicas y lo que conlleva a su elaboración. Durante el procesamiento de la información, se ha podido realizar el registro fotográfico del estado actual de las edificaciones y su contexto, por lo que se observa algunos cambios, debido a la mala conservación, destrucción etc. Se realizó también la fotografía con dron, para poder percibir con mejor claridad la magnitud y transformación del sector, y también para poder comparar con las fotografías aéreas del año 1944 del Servicio Aereofotográfico Nacional (SAN), en relación a su extensión.

En la prospección se pudo identificar en el Sector Tello, una organización de los espacios habitacionales muy concentrado y sectorizado, con división en subsectores, donde cada subsector tiene muros perimetrales. Los muros, en su mayoría de tapiales, forman paredes que separan estos recintos organizados ortogonalmente, cuya altura es de $2 \mathrm{~m}$ aproximadamente, dentro de ellas se encuentran los silos o cistas subterráneas en forma de botellas (estrechas en la boca y más anchos en la base), que son distanciados de unos a otros por $1.20 \mathrm{~m}$ y con una profundidad de hasta 4 $m$ en que se encontraron restos orgánicos, en especial el maíz de la chicha de jora (Segura, 2000). Actualmente se encuentra basura y evidencias de chamanería en el interior producto de las actividades clandestinas. Observamos también estos muros de gran tamaño longitudinal como ejes perimétricos, que forman los pasadizos para los distintos espacios habitacionales, con un ancho de $2 \mathrm{~m}$ y una altura de $1.60 \mathrm{~m}$ aproximadamente; y las entradas a estos espacios sectorizados tienen una forma de herradura y una altura de $1.35 \mathrm{~m}$ aproximadamente.

Es necesario tener en cuenta que, para el lado sur, tenemos a la quebrada de Jicamarca, que en la actualidad es pocas veces activada en la estación de verano (enero-marzo) en años en que se presenta el Fenómeno del Niño, produciéndose algunas inundaciones en el sitio arqueológico o en los centros poblados contiguos al sitio (figura 21).

A continuación, presentamos la descripción de cada uno de los subsectores del sector Tello de Cajamarquilla. Debemos señalar que los autores que han investigado en Cajamarquilla como es el caso de Segura (2001) y Narváez (2004), no especifican en sus trabajos la propuesta de subsectorización del sector Tello. En el caso de Segura (2001), figura 3; presenta un plano del sector donde menciona la existencia de 8 sectores, los cuales no son detallados en su texto, por lo que no se puede conocer los criterios metodológicos utilizados ni la cantidad de unidades arquitectónicas que conforman cada uno de ellos. Por eso, hemos desarrollado una propuesta de subsectorización del sector Tello, teniendo como referencia la disposición y asociación directa de las unidades arquitectónicas. Debemos aclarar que casi todos los autores que han investigado en Cajamarquilla tienden por denominar a los diversos sectores 


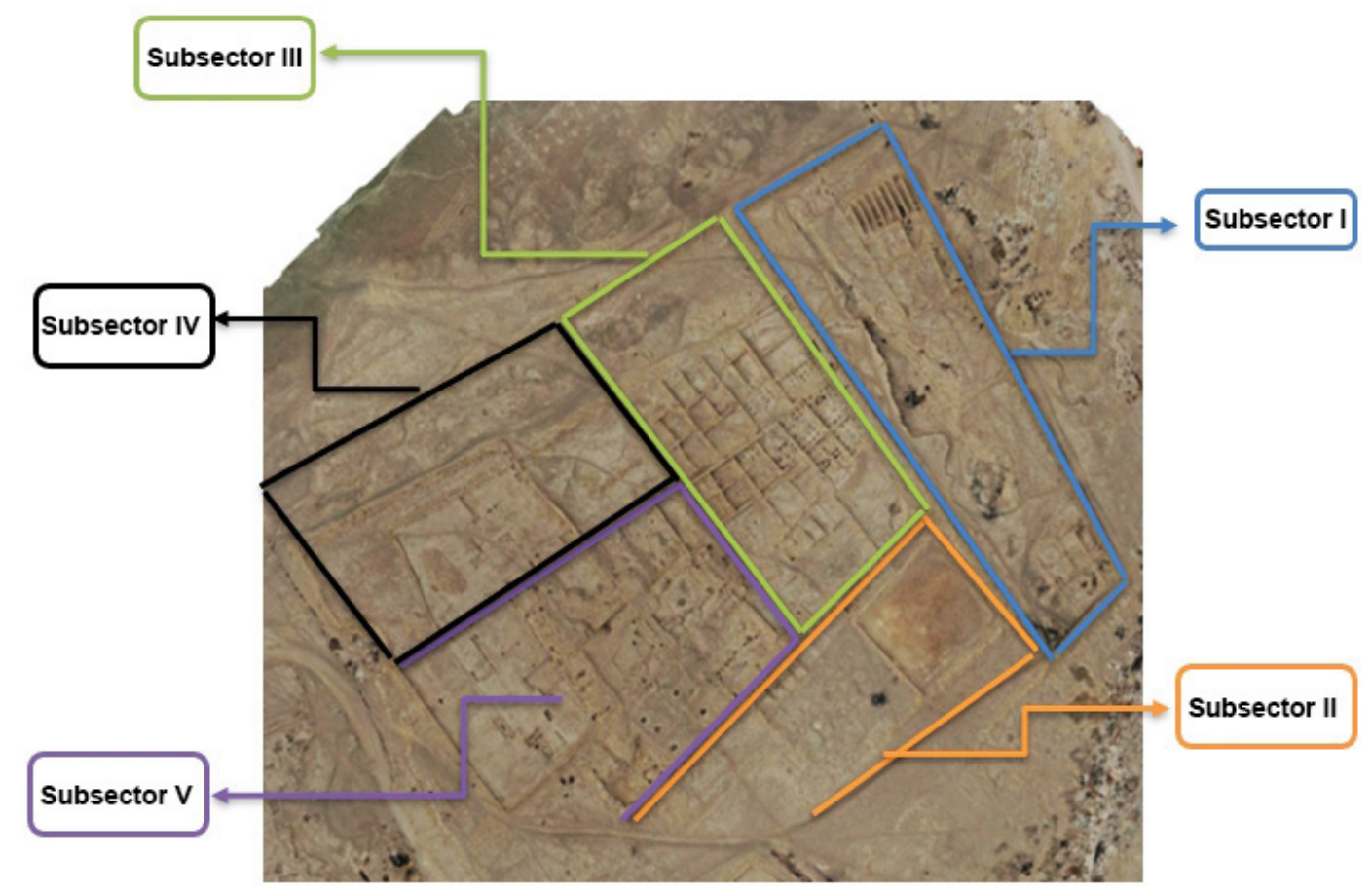

Figura 21. Subsectorización del Sector Julio C. Tello - Cajamarquilla, desde una vista de dron, donde se evidencia su trazo urbano y extensión.

como conjuntos arquitectónicos. Nosotros pensamos que las unidades de análisis secuenciales de lo general a lo particular, obedece al uso de las categorías siguientes: sitio Cajamarquilla, sector Julio C. Tello, subsectores (hemos identificado 5), conjuntos arquitectónicos (conjunto de recintos asociados entre sí), recintos / plazas / patios / otros, compartimientos (subdivisiones internas del recinto) y muros. Por ello, cuando nos referimos al sector Tello hacemos referencia al denominado por otros autores como conjunto arquitectónico Tello.

Subsector I: Se encuentra al noreste del sector Tello, tiene planta trapezoidal, siendo más ancho hacia el lado oeste. Tiene $260 \mathrm{~m}$ de largo (SE-NO) por entre 82 y 58 $\mathrm{m}$ de ancho (NE-SO). Está encerrado por muros perimétricos de tapiales de $1.79 \mathrm{~m}$ de alto, algunos de los cuales se extienden para servir de muros perimétricos a los otros subsectores contiguos, como es el caso de los muros norte y sur. En el interior presenta dos unidades arquitectónicas, el primero hacia el extremo sureste, conformado por siete recintos de planta cuadrangular y rectangular, con accesos simples mediante vanos que comunican el exterior o mediante pasadizos estrechos de aproximadamente $2 \mathrm{~m}$ de ancho. El recinto 1 es de planta trapezoidal, con $12 \mathrm{~m}$ de largo (NE-SO) por $10 \mathrm{~m}$ de ancho (NO-SE). El recinto 2 tiene planta cuadrangular ubicado al este del anterior, teniendo $8 \mathrm{~m}$ de largo (NO-SE) por $8.05 \mathrm{~m}$ de ancho (NE-SO). El 
recinto 3 se ubica al este del recinto 2, tiene planta rectangular, con $18 \mathrm{~m}$ de largo (NO-SE) por $10 \mathrm{~m}$ de ancho (NE-SO). El recinto 4 se ubica al sureste del anterior, tiene planta rectangular, con $14 \mathrm{~m}$ de largo (NE-SO) por $9.60 \mathrm{~m}$ de ancho (NO-SE), con muros a base de adobes, de hasta $1.89 \mathrm{~m}$ de alto; presenta un pequeño compartimiento cuadrangular en la esquina suroeste. Paralelo al muro sur del recinto 4 se aprecia un pasadizo que discurre en eje suroeste - noreste, mediante el cual se accede tanto al recinto 4 como al recinto 5 . El recinto 5 se ubica al noreste del recinto 4 , tiene planta cuadrangular, con $10.12 \mathrm{~m}$ de largo (NO-SE) por $8.20 \mathrm{~m}$ de ancho (NE-SO). El recinto 6 se ubica al sureste del recinto 5 , tiene planta rectangular, sin muro al lado sureste, por donde se comunica con un ancho pasadizo cuyo largo es entre $6 \mathrm{~m}$ y $20 \mathrm{~m}$ de largo, que comunica con el exterior; tiene $18 \mathrm{~m}$ de largo (NO-SE) por $10 \mathrm{~m}$ de ancho (NE-SO). Finalmente, el recinto 7 es el más grande, de planta rectangular, con 18.10 $\mathrm{m}$ de largo (NE-SO) por $12.20 \mathrm{~m}$ de ancho (NO-SE); se aprecia una extensión de su muro noroeste hacia el espacio abierto contiguo.

El segundo conjunto arquitectónico está ubicado en la esquina noreste del subsector, conformada por cinco recintos complejos, el primero ubicado al extremo noroeste de la unidad arquitectónica, planta rectangular, $38 \mathrm{~m}$ de largo (NE-SO) y $10 \mathrm{~m}$ de ancho (NO-SE). El recinto 2 se ubica paralelo al anterior, también de forma rectangular, con $38 \mathrm{~m}$ de largo (NE-SO) y $14 \mathrm{~m}$ de ancho (eje noroeste), al que se accede mediante un pasadizo que proviene del lado sureste y que a su vez comunica con los compartimientos del recinto 3 . El recinto 3 está ubicado al sureste del anterior, conformado por siete compartimientos rectangulares delgados, dispuestos en eje perpendicular a los recintos 1 y 2, posiblemente áreas de almacenamiento. El recinto 4 está conformado por cinco compartimientos paralelos dispuestos juntos (hacia el NE). Hacia el noreste discurre un pasadizo en eje NE - SO, mediante el cual se accede a los recintos 4 y 5 . Finalmente el recinto 5 es de planta rectangular con su mayor longitud en el eje NE - SO, conformado por un pequeño compartimiento rectangular y un patio.

Subsector II: Está conformado por dos grandes patios cuadrangulares, uno de ellos (del lado SO) contiene ocho compartimientos cuadrangulares distribuidos en dos hileras de cuatro cada uno, siendo posibles áreas de almacenamiento. Desde este patio se accede a través de un pasadizo (que tiene en una sección asociados cuatro recintos dispuestos alineadamente) al segundo patio, también de planta cuadrangular. Los muros que delimitan estos espacios están edificados a base de tapiales elaborados por paños murarios superpuestos. El acceso a este subsector se da a través de un pasadizo dispuesto en eje oeste - este, ubicado en el extremo noroeste del subsector, desde donde también se puede acceder a la pirámide del subsector III. El patio 1 tiene $58 \mathrm{~m}$ de largo (N-S) por $54 \mathrm{~m}$ de ancho (E-O); mientras que el patio 2 tiene $68 \mathrm{~m}$ de largo (N-S) por $58 \mathrm{~m}$ de ancho (E-O) (figuras 22 y 23). 


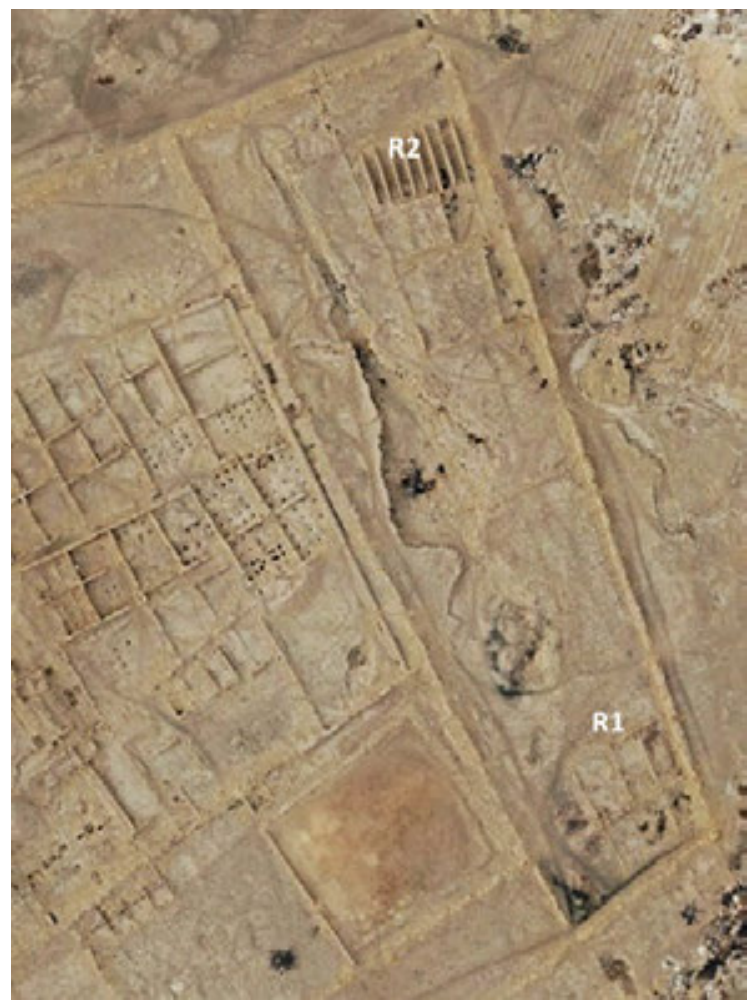

Figura 22. Subsector 1, Sector Tello.

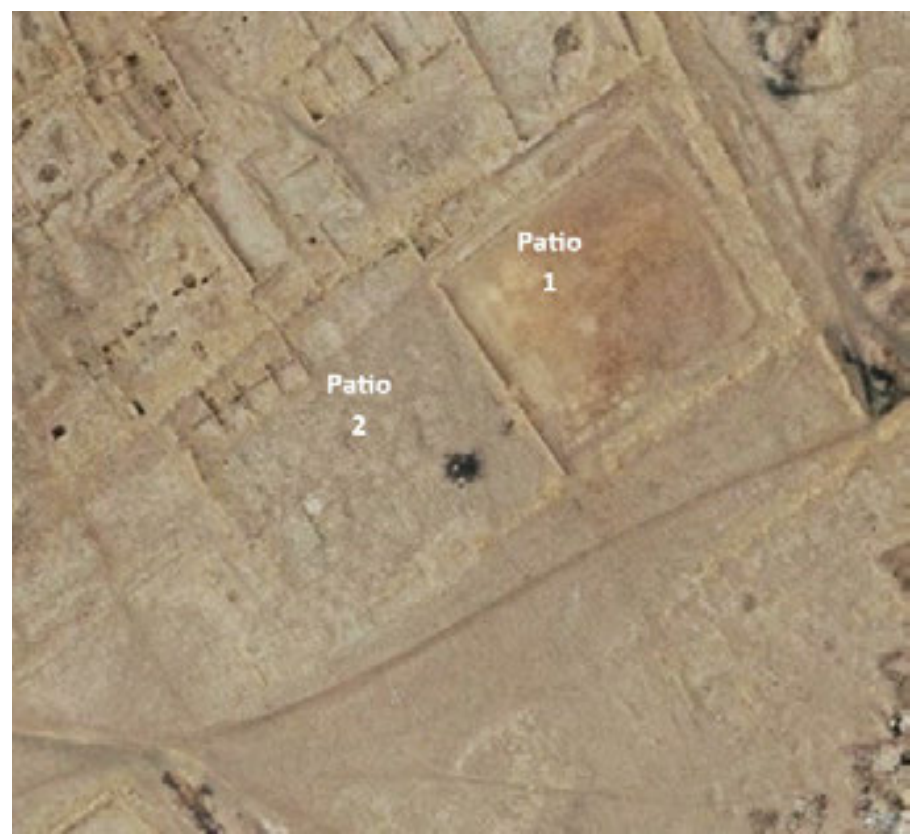

Figura 23. Subsector I, compuesto por dos posibles patios, Sector Tello. 
Subsector III: Se encuentra ubicado en la parte central del sector, conformado por 5 conjuntos arquitectónicos. El primero se ubica en el extremo sur del subsector (limitando con el subsector II), conformado por un recinto de dos compartimientos concéntricos en la esquina suroeste, asociado a un patio y cinco compartimientos rectangulares alineados en eje este - oeste dispuestos en la esquina noreste del conjunto. Inmediatamente al este se aprecia un patio rectangular, al cual se accede a través de una calle lateral interna de $8 \mathrm{~m}$ de ancho y $12.40 \mathrm{~m}$ de largo, que discurre en eje norte-sur, desde el cual se accede a casi todos los espacios de este subsector.

El conjunto arquitectónico 2 está conformado por el recinto 1, de $14 \mathrm{~m}$ de largo (EO) por $10 \mathrm{~m}$ de ancho, ubicado en el extremo noroeste del conjunto, formado a su vez por tres compartimientos internos. El acceso a este recinto 1 se da desde el recinto 2 ubicado inmediatamente al sur, de planta cuadrangular, de $14 \mathrm{~m}(\mathrm{E}-\mathrm{O})$ por $12 \mathrm{~m}(\mathrm{~N}-$ $\mathrm{S})$, conteniendo un compartimiento interno. El recinto 3 se ubica inmediatamente al este del recinto 1, de planta rectangular, de $14 \mathrm{~m}$ de largo (E-O) por $10 \mathrm{~m}$ de ancho (N-S). El recinto 4 se ubica al este del anterior, de planta rectangular, de $12 \mathrm{~m}$ de largo (E-O) por $10 \mathrm{~m}$ de ancho (eje norte-sur). El recinto 5 se ubica al este del 4, también de planta rectangular, de $14 \mathrm{~m}$ de largo (E-O) por $9 \mathrm{~m}$ de ancho (N-S). El recinto 6 se ubica al sur del recinto 3, de planta rectangular, de $14 \mathrm{~m}$ de largo (E-O) por $11 \mathrm{~m}$ de ancho (N-S). El recinto 7 se ubica al sur del recinto 4, de planta rectangular, de $12 \mathrm{~m}$ de largo (E-O) por $10 \mathrm{~m}$ de ancho (N-S). El recinto 8 se ubica al sur del recinto 5, de planta rectangular, de $14 \mathrm{~m}$ de largo (E-O) por $10 \mathrm{~m}$ de ancho (N-S), de este recinto se accede al recinto 5 . Se aprecian espacios que han sido excavados en temporadas anteriores y se encuentran expuestas, deteriorando las edificaciones halladas. En muchos de estos recintos se ha identificados silos o cistas subterráneas de más de 1 metro de profundidad, como en el recinto 3 que tiene 11 silos dispuestos ordenadamente (en alineamientos), en el recinto 4 que tiene 6 silos dispuestos sin un ordenamiento aparente, mientras que en el recinto 5 se aprecian 10 silos dispuestos heterogéneamente al interior del espacio. Estos 8 recintos se encuentran contiguos y asociados entre sí, separados de otros tres recintos y un patio por un pasadizo dispuesto en eje este oeste, el cual tiene diversa anchura en toda su extensión, adecuándose a la forma y contorno de los recintos, desde el cual se accede a los 8 recintos descritos y a los otros tres ubicados al sur. Inmediatamente al sur del pasadizo se encuentra el recinto 9, de planta rectangular, con mayor longitud en el eje este - oeste, de $24 \mathrm{~m}$ de largo (E-O) por $6 \mathrm{~m}$ de ancho (N-S), cuyo acceso se ubica en la esquina sureste. El recinto 10 es de planta cuadrangular, ubicado al sur del recinto 9, con ligera amplitud en su lado norte, tiene $14 \mathrm{~m}(\mathrm{E}-\mathrm{O})$ por $12 \mathrm{~m}$ de ancho (N-S). El recinto 11 se ubica inmediatamente al oeste del recinto 10 , es de planta cuadrangular (con ligera amplitud hacia el lado oeste), de $16 \mathrm{~m}$ de largo (E-O) por $15 \mathrm{~m}$ (N-S). Inmediatamente hacia el oeste del recinto 11 se aprecia un patio de medianas dimensiones y planta trapezoidal, de 28 $\mathrm{m}$ de largo (E-O) por $26 \mathrm{~m}$ de ancho (N-S). También se aprecian en este patio 12 silos dispuestos en la parte media del mismo (figuras del 24 al 28). 


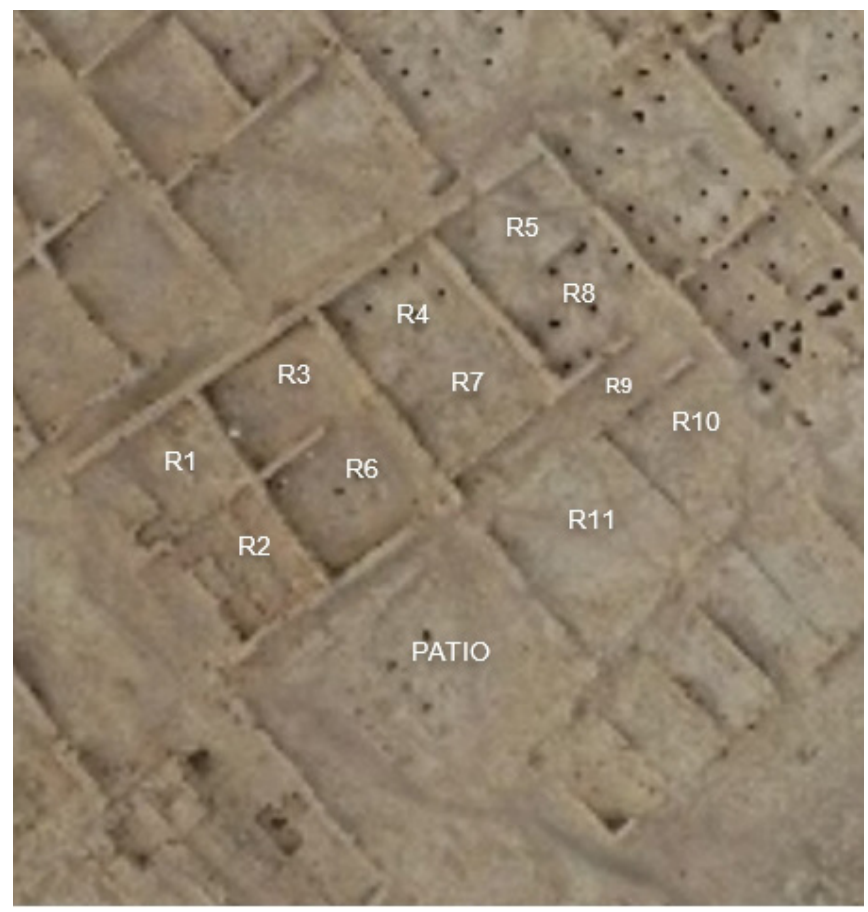

Figura 24. Subsector III, Sector Tello.

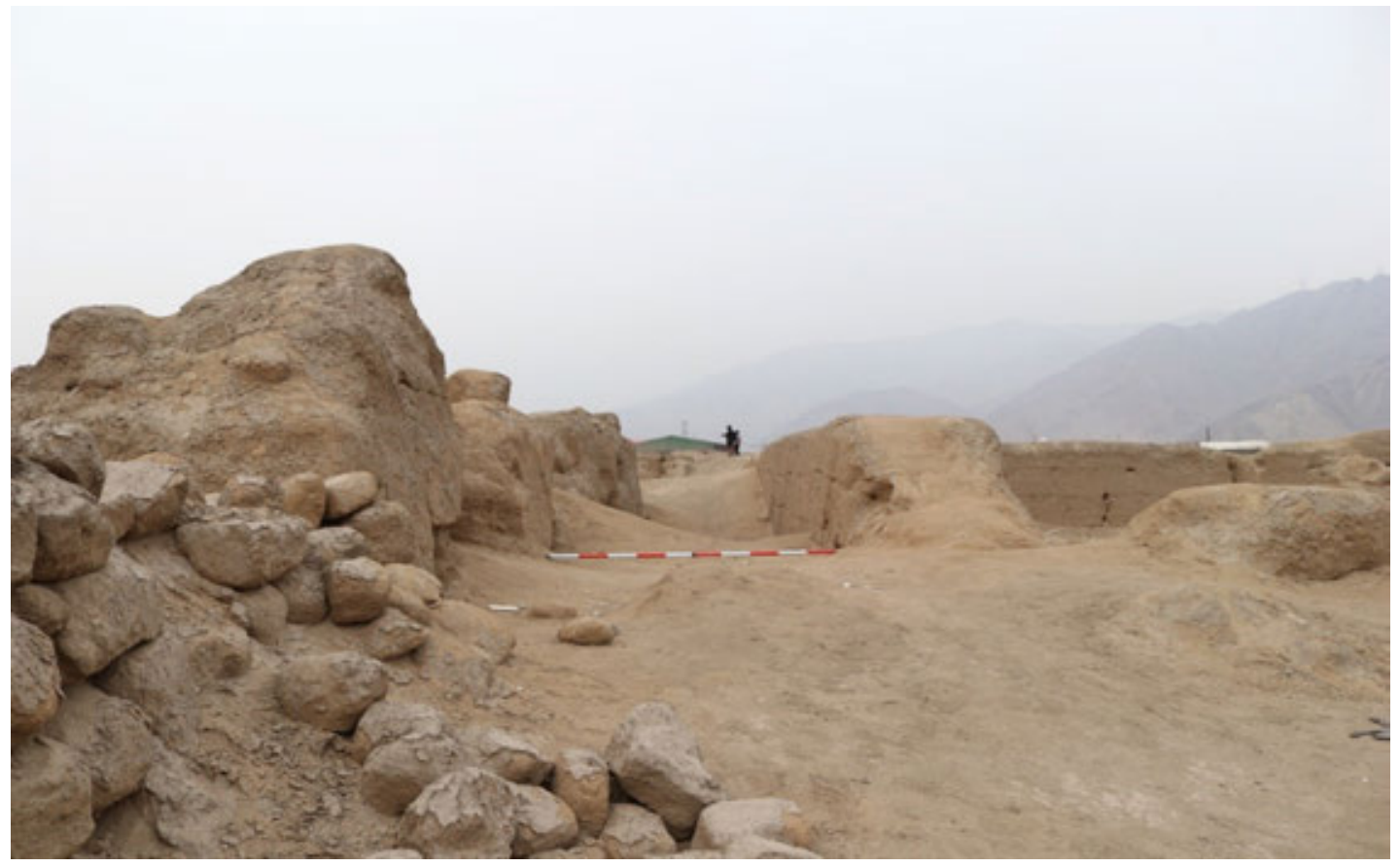

Figura 25. Pasadizo principal del sector III del conjunto Tello, con un ancho de 2 m aproximadamente. 


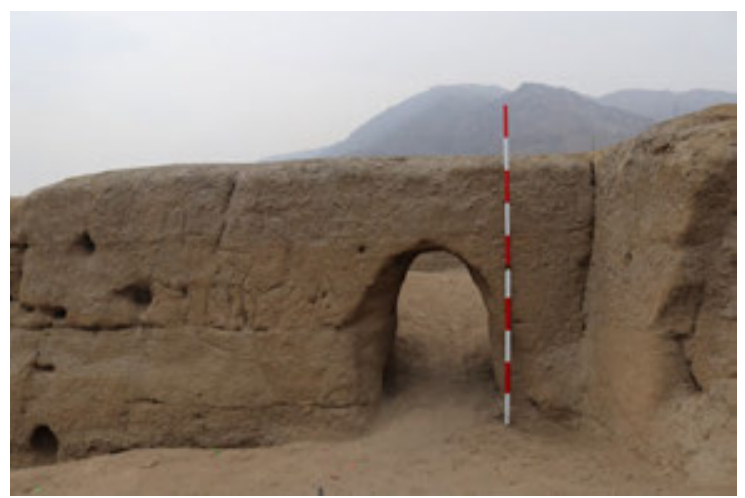

Figura 26. Vano en forma de herradura, subsector III, sector Tello

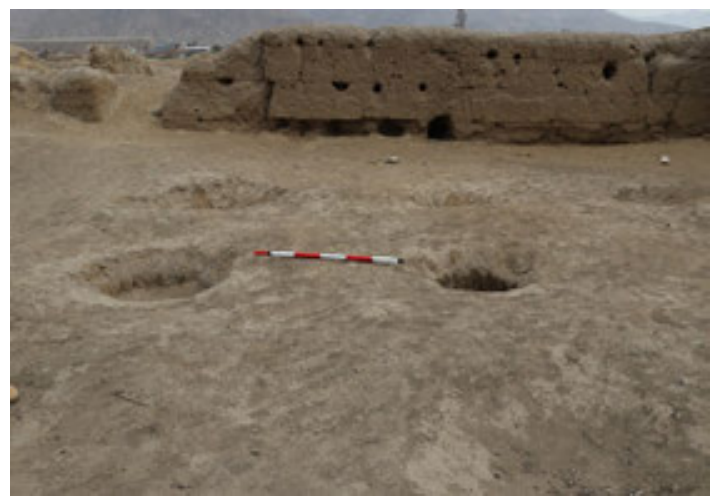

Figura 27. Silos o cistas, en el subsector III, Sector Tello.

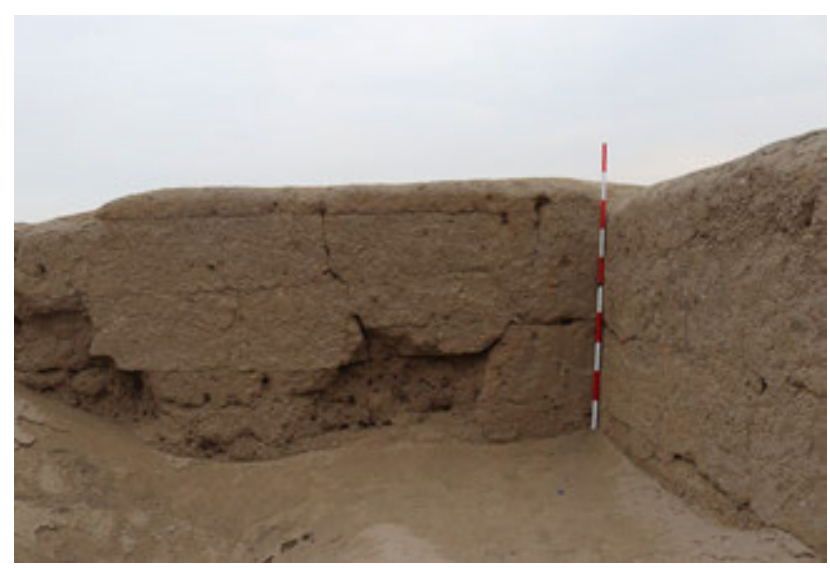

Figura 28. Muro de abodones, Subsector Tello.

El conjunto arquitectónico 3 está ubicado inmediatamente hacia el este del anterior, conformado por 4 sectores. El recinto 1 se ubica en la esquina noroeste del conjunto, de $20 \mathrm{~m}$ de largo (N-S) por $16 \mathrm{~m}$ de ancho (E-O), presentando 19 silos dispersos en toda su área de manera ordenada (alineados). El recinto 2 se ubica inmediatamente al este del anterior, de planta cuadrangular, de $16 \mathrm{~m}$ de largo (E-O) por $15 \mathrm{~m}$ de ancho (N-S), conteniendo 22 silos ordenados en su interior, algunos muy destruidos por huaqueo. En general el diámetro de la boca de estos silos es de entre 0.50 y $0.60 \mathrm{~m}$ de diámetro. Inmediatamente al norte de este recinto se aprecia un pasadizo de $2 \mathrm{~m}$ de ancho por $18 \mathrm{~m}$ de largo que comunica el exterior del conjunto con el interior de estos recintos. El recinto 3 se ubica inmediatamente al sur del recinto 2, tiene planta rectangular, con $16 \mathrm{~m}$ de largo (N-S) por $12 \mathrm{~m}$ de ancho (E-O), presentando 13 silos dispuestos ordenadamente en su interior. Por su parte el recinto 4 se ubica al oeste del recinto 3, de planta rectangular, de $18 \mathrm{~m}$ de largo (N-S) por $16 \mathrm{~m}$ de ancho (E-O), presentando 4 compartimientos internos y 21 silos en el interior de estos (figura 29). 


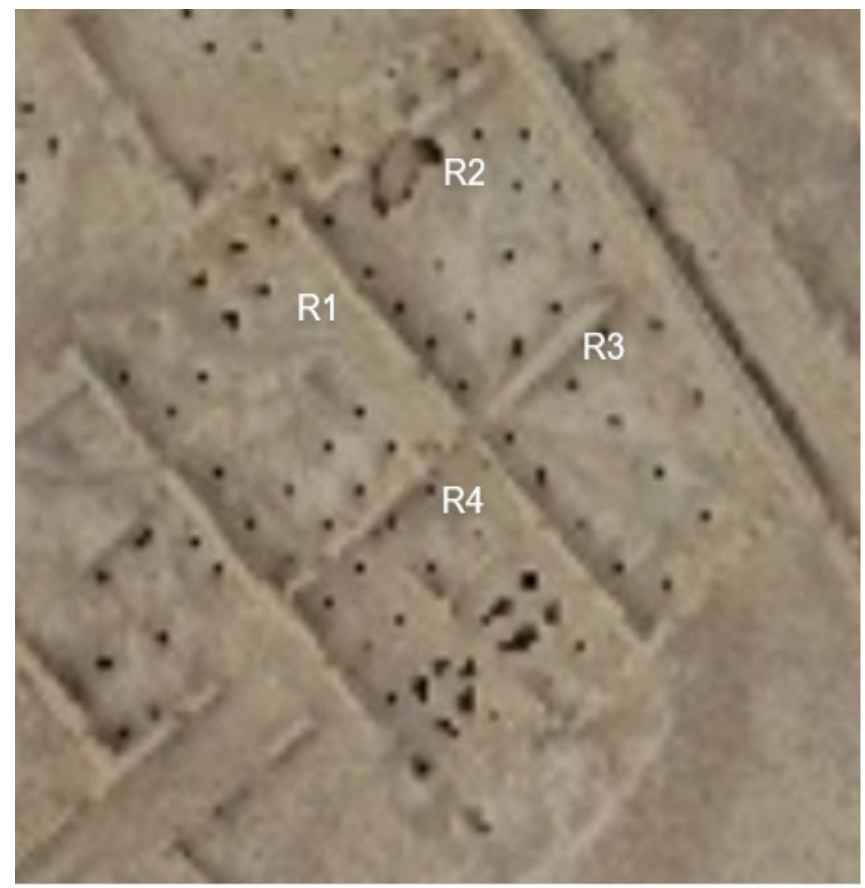

Figura 29. Conjunto arquitectónico 3, subsector III, sector Tello.

El conjunto arquitectónico 4 se ubica al norte de los conjuntos 2 y 3. Entre estos hay un extenso pasadizo de $4 \mathrm{~m}$ de ancho por $58 \mathrm{~m}$ de largo. Presenta 18 recintos interconectados entre sí por pasadizos y vanos de acceso, siendo la mayoría de planta rectangular, en especial los ubicados en el lado norte, siendo los más extensos los recintos 6, 13 y 18, ubicados en el extremo sur del conjunto; como el recinto 13 que tiene $22 \mathrm{~m}$ de largo (E-O) por $19 \mathrm{~m}$ de ancho (N-S). En los recintos 13, 18 y 17 se aprecian numerosos silos, identificándose 13, 23 y 5 silos respectivamente (figura 30).

En la parte posterior de este conjunto de recintos se ubica una plaza de medianas dimensiones, cercada por los lados de planta rectangular, de $101 \mathrm{~m}$ de largo (E-O) por $30 \mathrm{~m}$ (N-S). En el interior se aprecian 3 silos distribuidos desordenadamente.

El subsector IV: Está conformado por dos áreas bien definidas: en primer lugar, la estructura piramidal de más de $7 \mathrm{~m}$ de altura con respecto al resto de edificaciones, y en segundo lugar, los dos patios asociados a la pirámide que se ubican inmediatamente hacia el lado suroeste, ubicados a diferentes niveles. Hacia el lado norte del subsector, en la parte baja de la pirámide se aprecia un patio de planta rectangular, de $30 \mathrm{~m}$ de largo (NO-SE) por $16 \mathrm{~m}$ de ancho (NE-SO), al cual se accede a través de un pasadizo proveniente del subsector III. Inmediatamente al oeste de este recinto se eleva la pirámide, sobre la cual se aprecian ocho recintos, dispuestos todos en forma casi cuadrangular y cada uno con la misma planta. Toda la cima de la pirámide mide $90 \mathrm{~m}$ de largo (E-O) por $78 \mathrm{~m}$ de ancho (N-S). Hacia el lado este se 
aprecian cinco de estos recintos asociados entre sí, posiblemente se trate de áreas residenciales, tienen planta cuadrangular. El recinto 1 tiene planta rectangular, con $30 \mathrm{~m}$ de largo (NO-SE) por $20 \mathrm{~m}$ (NE-SO), mientras que el recinto 4 tiene $28 \mathrm{~m}$ de largo (NO-SE) por $24 \mathrm{~m}$ de ancho (NE-SO). El recinto 3 tiene cuatro pequeños compartimientos a los que se accede mediante pasadizos pequeños.

Hacia el lado sureste se aprecia un extenso recinto de planta cuadrangular, el cual se emplaza en la ladera de la pirámide. Presenta un pequeño compartimiento rectangular hacia su lado oriental, así como un pequeño pasadizo por el cual se accede a los otros recintos de la cima. Este recinto tiene $54 \mathrm{~m}$ de largo (NE-SO) por 40 $m$ de ancho (NO-SE).

El conjunto arquitectónico 3 se ubica también en la cima de la pirámide (lado So), conformado por tres recintos, siendo el primero de planta trapezoidal, de $30 \mathrm{~m}$ de largo (NO-SE) por $28 \mathrm{~m}$ de ancho (eje noreste - suroeste); el segundo es rectangular, de $34 \mathrm{~m}$ de largo (NE-SO) por $8 \mathrm{~m}$ de ancho (NO-SE); mientras que el tercero dispuesto en forma alineada con los otros dos, tiene planta rectangular, de $44 \mathrm{~m}$ de largo (NO-SE) por $34 \mathrm{~m}$ de ancho (NE-SO).

El conjunto arquitectónico 4 tiene planta rectangular, conformado por tres recintos y un patio de planta irregular, ubicado en la parte baja de la pirámide, siendo los recintos 1 y 2 de planta cuadrangular y tamaño mediano (el primero de 18 por 16 $\mathrm{m}$ y el segundo de 20 por $22 \mathrm{~m}$ ); por su parte, el tercero es de $22 \mathrm{~m}$ de largo (NE-SO) por $12 \mathrm{~m}$ de ancho (NO-SE) y planta rectangular. El recinto 4 tiene planta cuadrangular con $12 \mathrm{~m}$ de largo (NO-SE) por $12 \mathrm{~m}$ de ancho (NE-SO). Por debajo del nivel de estos recintos se aprecia un patio de grandes dimensiones con forma en "L", adaptándose a la topografía y gradiente de la sección media de la pirámide, aunque con su mayor extensión sobre una plataforma en la esquina sur de la estructura. Este patio tiene $40 \mathrm{~m}$ de largo (NO-SE) por $34 \mathrm{~m}$ de ancho (NE-SO), con una extensión hacia el lado NO de $82 \mathrm{~m}$.

El conjunto arquitectónico 5 está conformado por dos plazas grandes dispuestas contiguamente y por debajo del nivel de la pirámide, aunque la plaza 2 se encuentra a $1.50 \mathrm{~m}$ por encima del nivel del primero y sobre una superficie no horizontal, pues presenta una regular gradiente. La plaza 1 tiene planta rectangular, con 85 $\mathrm{m}$ de largo (NO-SE) por $28 \mathrm{~m}$ de ancho (NE-SO), mientras que la plaza 2 tiene $82 \mathrm{~m}$ de largo (NO-SE) por $34 \mathrm{~m}$ de ancho (NE-SO); ambos patios están divididos por un muro de tapiales (figura 31).

El subsector V: Se ubica en la parte posterior de la estructura piramidal, extremo occidental del sector. Está conformado por cinco espacios, al parecer se trata de patios o plazas pequeñas, de formas diversas. El más grande se ubica en el lado noreste, abierto hacia su extremo oeste, donde no presenta muros, teniendo $132 \mathrm{~m}$ de largo (NE-SO) por $42 \mathrm{~m}$ de ancho (NO-SE). Junto a este se encuentra otro espacio rectangular muy delgado, de $110 \mathrm{~m}$ de largo (NE-SO) por $12 \mathrm{~m}$ de ancho (NO-SE). 
Inmediatamente al sureste se aprecia un alineamiento de tres espacios emplazadas sobre plataformas continuas, el espacio 3 tiene planta cuadrangular, de $58 \mathrm{~m}$ de largo (NO-SE) por $54 \mathrm{~m}$ de ancho (NE-SO); el espacio 4 tiene planta rectangular, de $78 \mathrm{~m}$ de largo (NO-SE) por $52 \mathrm{~m}$ de ancho (NE-SO); mientras que el espacio 5 tiene planta pentagonal (con un lado cóncavo), de $52 \mathrm{~m}$ de largo (NE-SO) por $44 \mathrm{~m}$ de ancho (NO$\mathrm{SE}$ ). Los muros de este subsector son a base de tapiales, con alturas de hasta $2.00 \mathrm{~m}$ aproximadamente (figura 32).

En varias secciones de este sector se aprecian áreas de reutilización, lo cual fue reportado también por otros investigadores, (Narváez, 2004; Segura, 2001; Mogrovejo, 1997; Sestieri, 1963), observándose las ocupaciones del Horizonte Medio y del Intermedio Tardío, aunque se observa también en los hoyos de las excavaciones pasadas que se encuentran aún expuestas, los adobitos de la ocupación Lima y en la superficie los tapiales y la yapana. Muchos de los recintos presentan banquetas internas.

Las técnicas arquitectónicas evidenciadas en el sector Tello las diferenciamos en 5 tipos, para lo cual nos guiamos con las propuestas de Villar Córdova (1935) y Narváez (2004):

TIPO 1: Corresponde a los muros edificados a base de adobitos paralelepípedos, técnica constructiva característica de la cultura Lima presente en los asentamientos del Periodo Intermedio Temprano del Valle de Lima. Consiste en la colocación de los adobitos en posición vertical, unidos con o sin argamasa, en los que se conoce como "técnica del librero" (Villar Córdova, 1935). Mogrovejo (1997), señala que esta arquitectura corresponde a la ocupación Lima del sitio (figura 33).

TIPO 2: Corresponde a los muros elaborados a base de tapiales compactos en un solo bloque constructivo, de sección recta. Esta arquitectura ha sido identificada en varios subsectores de Tello, en especial en la pirámide. Este tipo, según Mogrovejo (1997), también corresponde a la ocupación Lima del sitio, aunque basándonos en los datos reportados por otros autores pensamos que correspondería al Horizonte Medio (van Dalen, 2012b).

TIPO 3: Muros confeccionados con tapiales, elaborados mediante la técnica de los paños murarios de sección trapezoidal, de mayor longitud, observándose la unión de los bloques de cada paño. Se trata de la arquitectura más común en el sector Tello delimitando recintos, pasajes, calles, patios, entre otros. Este tipo, según Mogrovejo (1997), correspondería a la ocupación Tardía del sitio, propuesta con la que concordamos (figura 34).

TIPO 4: Edificaciones elaboradas a base de bloques de yapana cortadas y unidas con argamasa de barro. Se trata de edificaciones simples que encierran recintos medianos o muros de contención de las plataformas de la pirámide. Estos muros corresponden a la reocupación tardía del sitio (figura 35). 


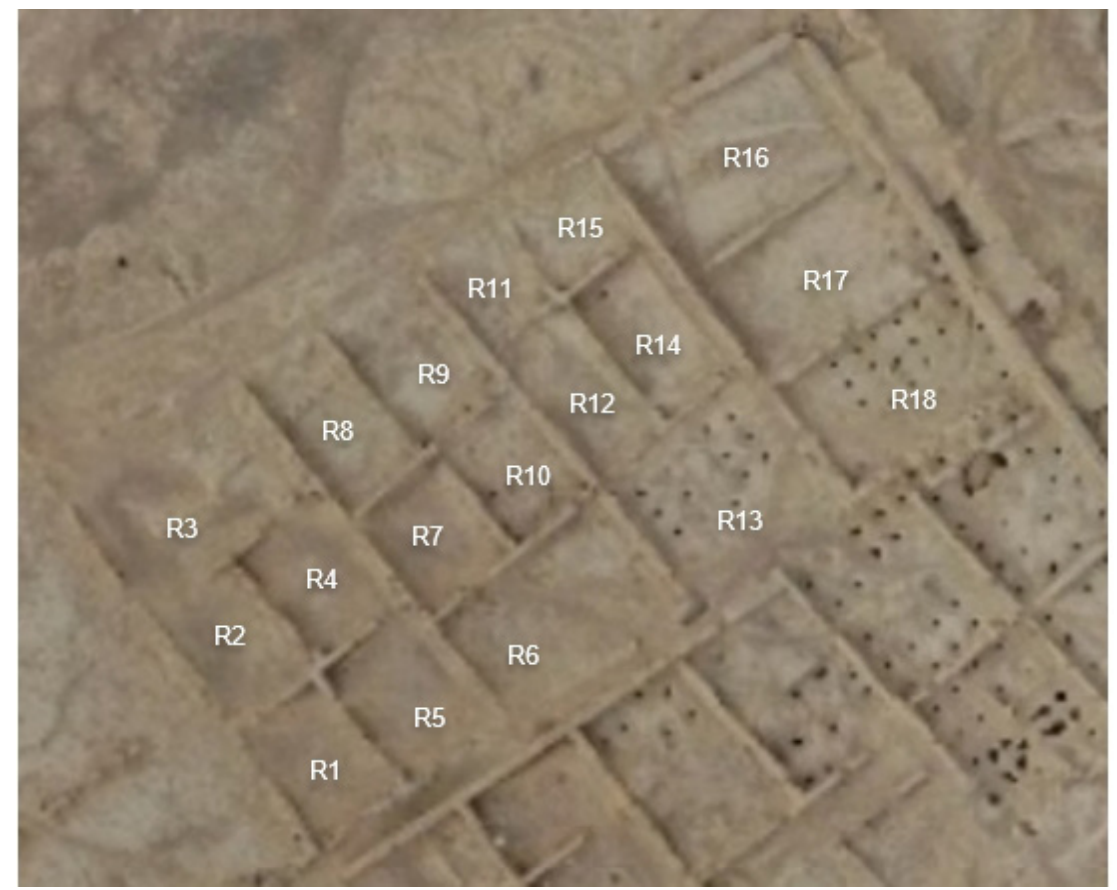

Figura 30. Conjunto arquitectónico 4, subsector III, sector Tello.

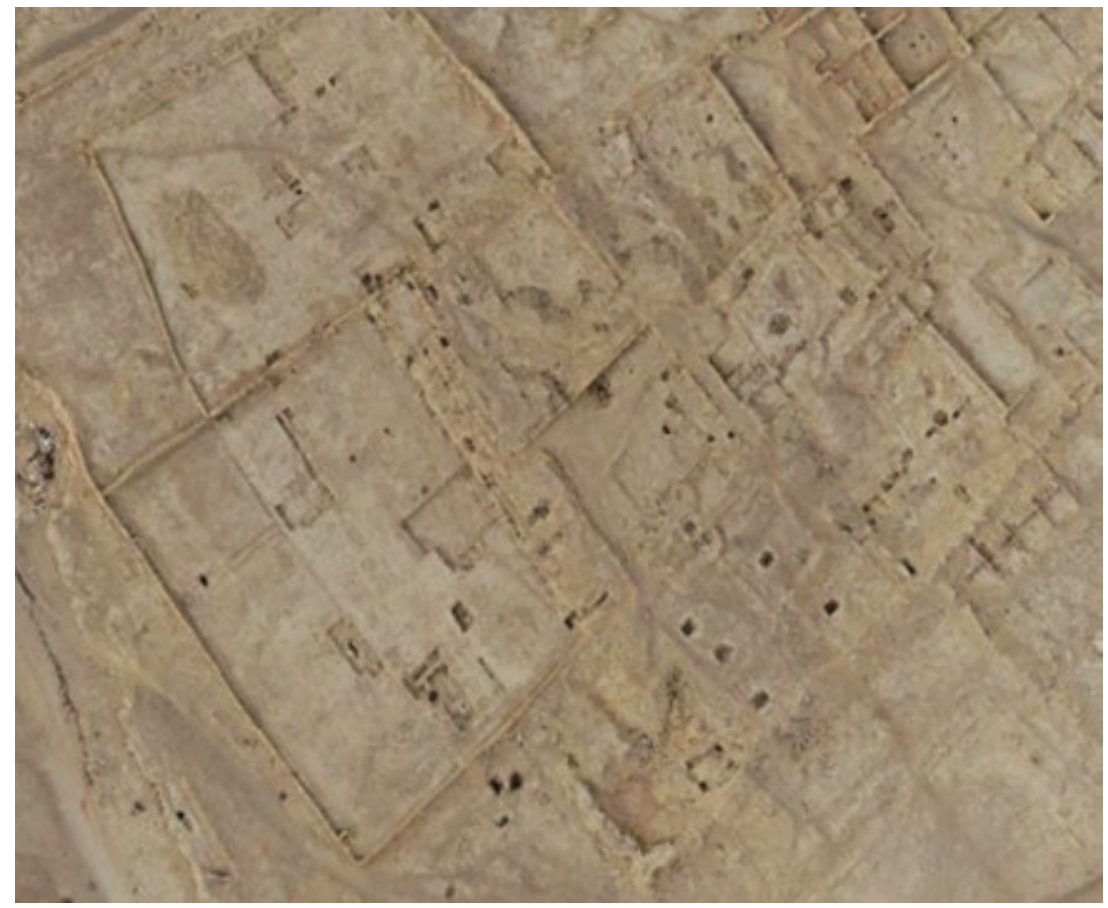

Figura 31. Subsector IV, sector Tello. 


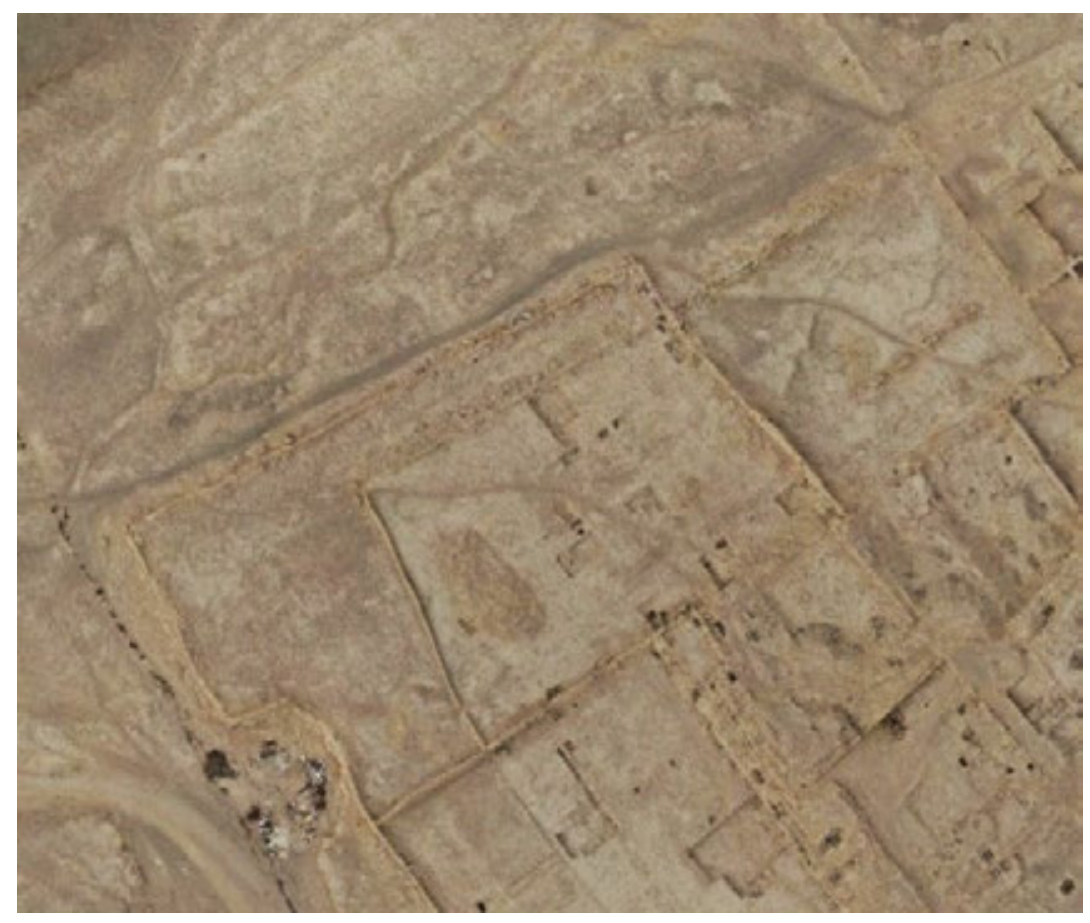

Figura 32. Subsector V, sector Tello.

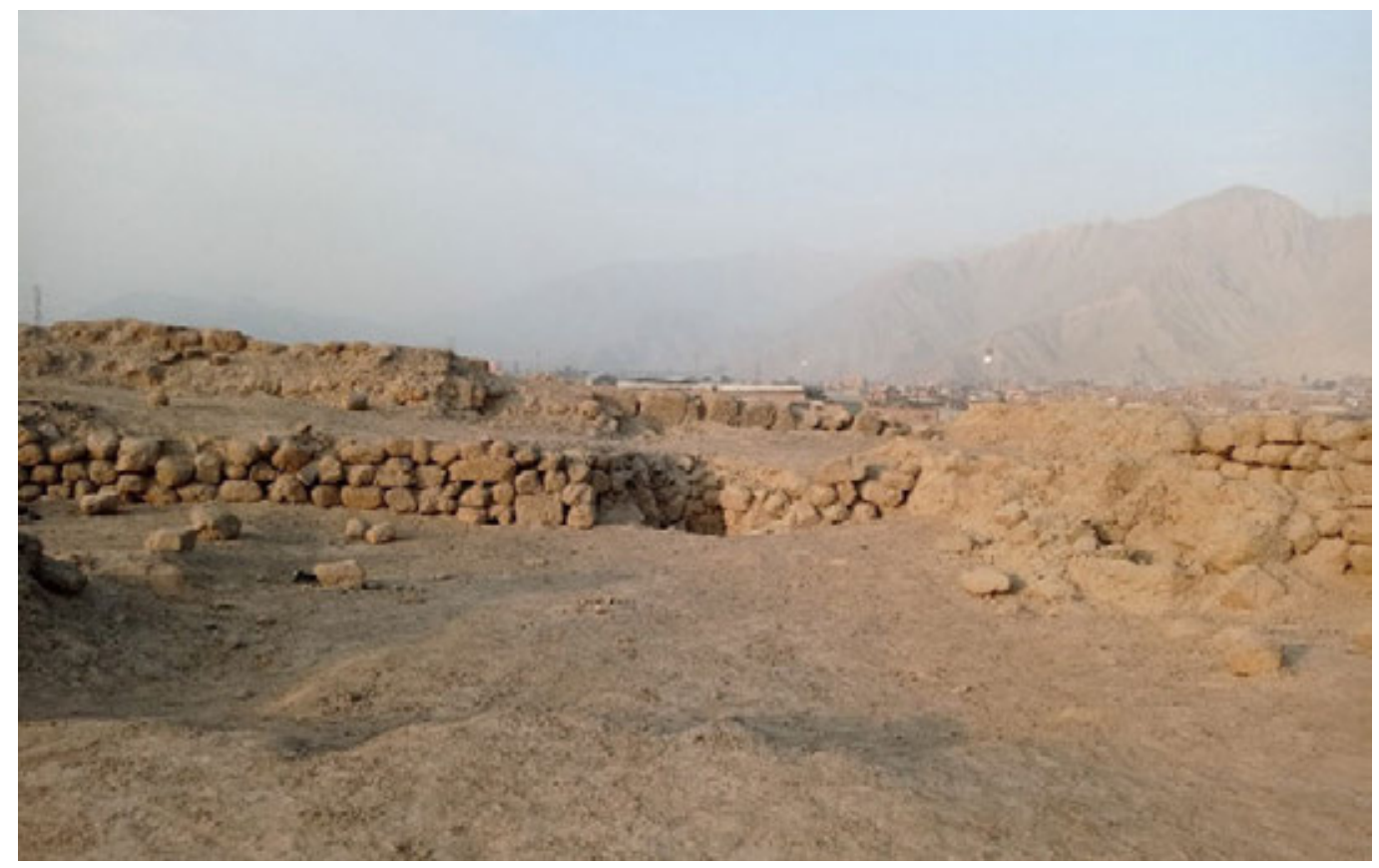

Figura 33. Presencia de adobitos, subsector IV, sector Tello. 


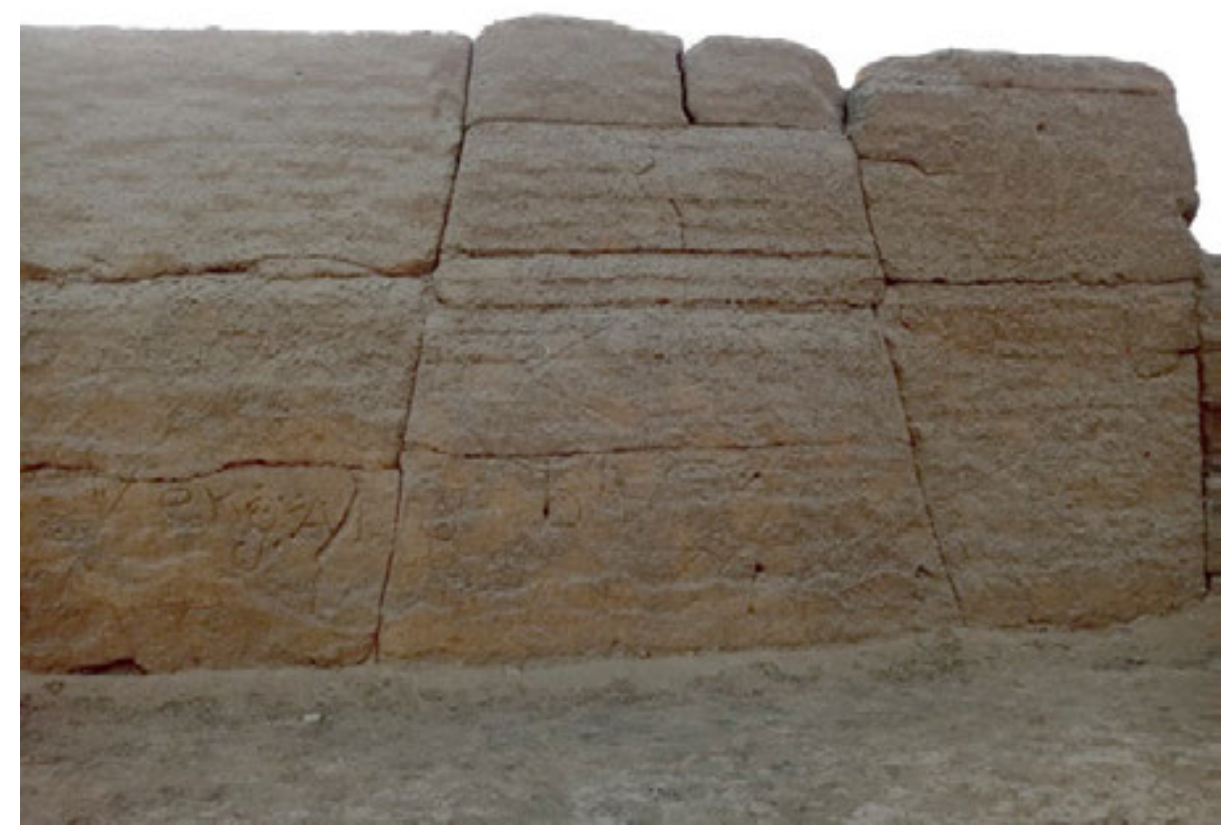

Figura 34. Presencia de adobones, patio subsector IV, sector Tello.

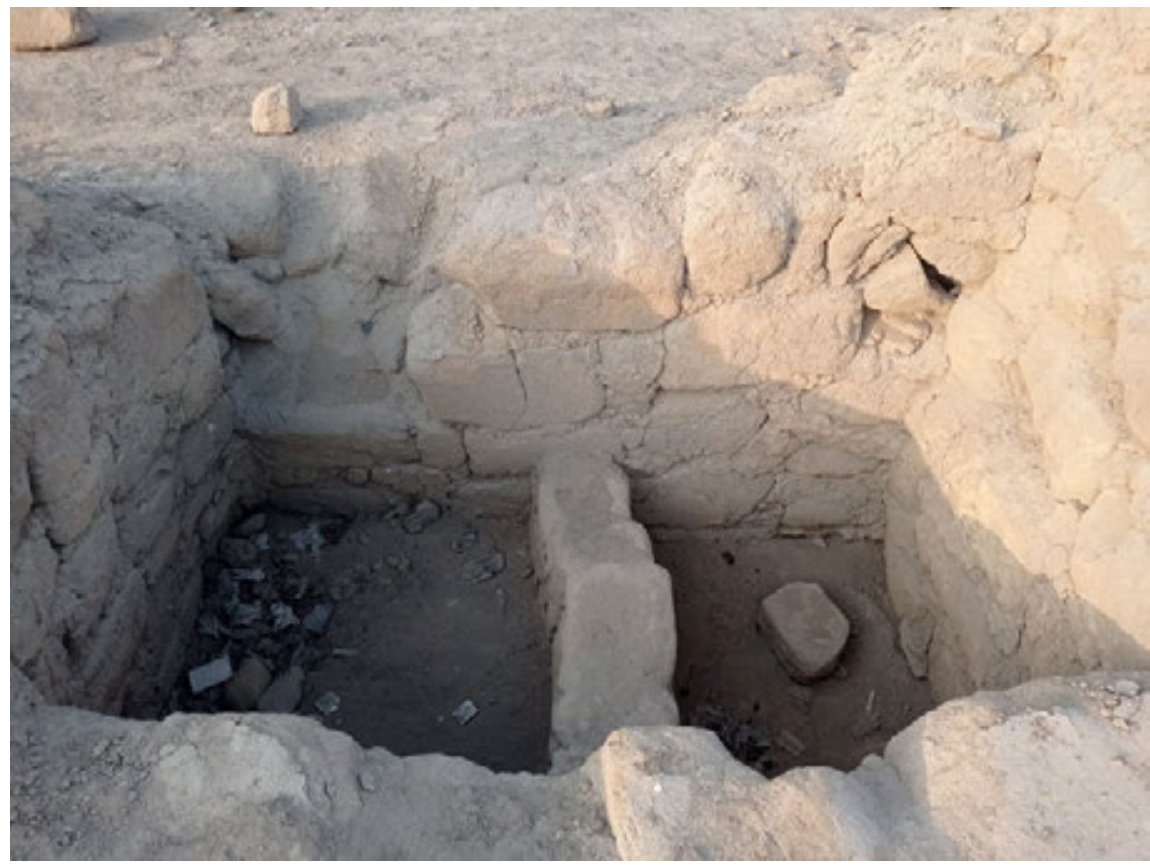

Figura 35. Presencia de adobitos, subsector IV, sector Tello. 
TIPO 5: Muros confeccionados con adobones grandes. Aparecen como aparejos murarios unidos con argamasa. Los adobones tienen iguales dimensiones, elaborados con moldes. Estas estructuras se asocian a las ocupaciones tardías del sitio (figura 36).

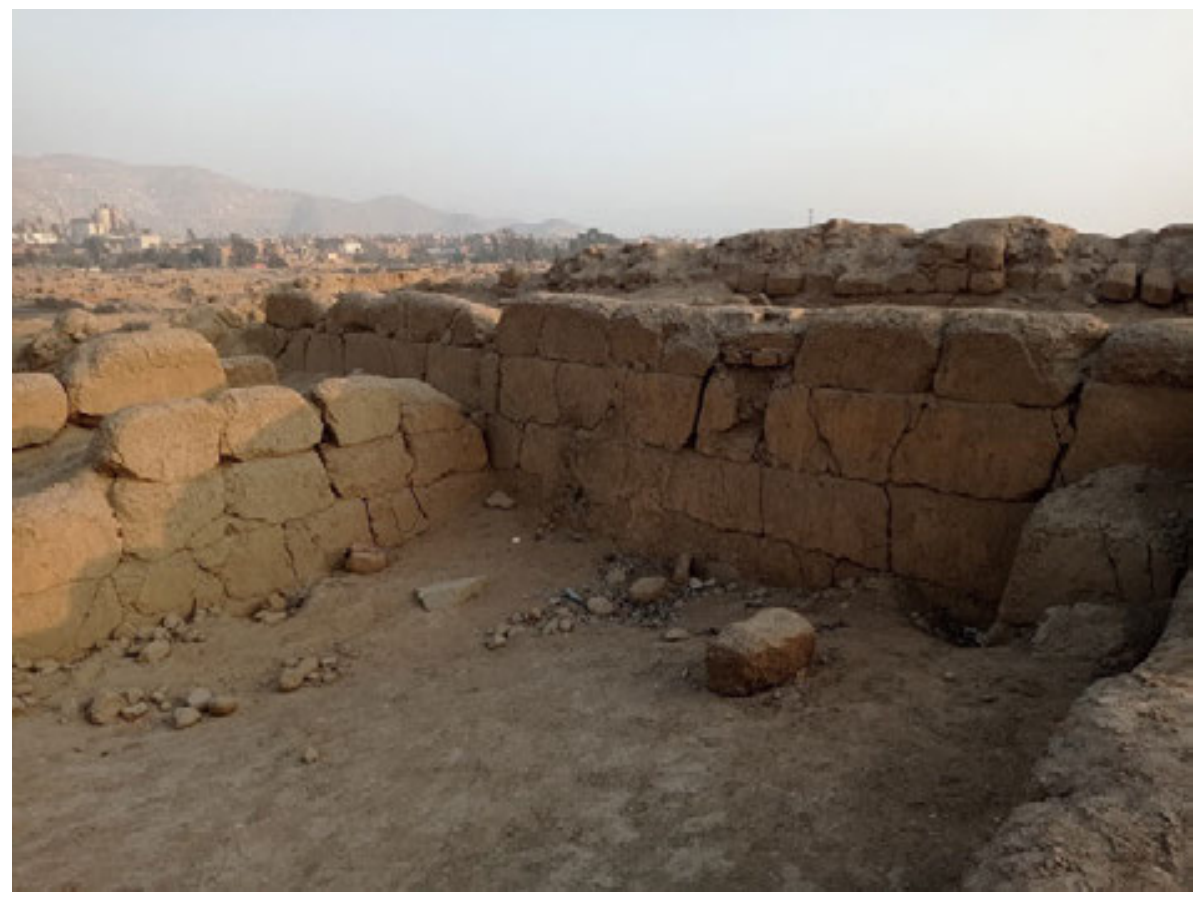

Figura 36. Presencia de adobones, subsector IV, sector Tello.

\section{IMPORTANCIA DE CAJAMARQUILLA DURANTE EL PERIODO INTERMEDIO TARDÍO}

Si bien en este trabajo de investigación, nuestro problema está relacionado a la secuencia cronológica a través de la arquitectura del tapial, en base a que muchos autores desde sus puntos de vista, entre ellos Bueno (1974-1975) que planteó que Cajamarquilla atravesó por 3 fases: Cajamarquilla I (Intermedio Temprano) que es vinculada a la "cultura Maranga"; Cajamarquilla II (Horizonte Medio) que lo relaciona a la época Wari (al igual que Lumbreras) y serían los grandes constructores de los edificios en el sitio, y; Cajamarquilla III (Intermedio Tardío) que supuestamente fue habitada por pobladores de origen serrano, rural y de arquitectura sencilla.

Con base en los resultados que presentamos en este trabajo de investigación, mediante informaciones bibliográficas, análisis del sitio y los materiales arquitectónicos en superficie, las fases más tempranas detectadas en el sitio corresponden 
a la cultura Lima en su fase más tardía (Patterson, 2014, pp. 167-172), pero no son solamente por las estructuras en adobitos sino principalmente en tapiales y corresponden a las grandes edificaciones piramidales. En cambio, la presencia Wari como apogeo en Cajamarquilla en el Horizonte Medio, es posible la influencia en el trazo urbano, pero en menor proporción, por la reutilización en diversos sectores, como de almacén a entierros con materiales de la época 1B-2 del Horizonte Medio (Mogrovejo, 1997) que son intrusivos en la pirámide ya abandonada como Tello (Narváez, 2004).

Finalmente, el Período Intermedio Tardío presenta gran complejidad y es responsable de las grandes edificaciones de tapiales en el sitio como los que se observan en el sector Tello, para el Horizonte Medio estos recintos cuadrangulares, agrupaban a estos silos de almacenamientos, con las estructuras de abobes compactados unos a otros formando los espacios, pero mientras el conjunto va creciendo, ganando extensión, vemos un cambio, pasando de adobones a tapiales de grandes dimensiones, muy característico de la cultura Ichma; además que tuvo una fuerte presencia en el valle de Rímac, formando estos cercos perimetrales, y además de la plaza principal que está al frontis de la pirámide está superpuesta o es más alto, y otro tipo de material que es el bloque de yapana cortadas y unidad con argamasa de barro, que forman parte de la estructura de plataformas extensas, que son atribuidas a las ocupaciones tardías.

En periodos prehispánicos tardíos (posiblemente desde mucho antes), las quebradas laterales eran vías de interconexión natural o cultural (con la habilitación de caminos muy bien elaborados) por donde se realizaban estas interacciones culturales o comerciales. Así, las grandes quebradas son corredores de fácil acceso por donde las personas o caravanas comerciales transitaban para el intercambio de productos andinos hacia la costa, siendo las áreas de encuentro (tinkuy) algunas secciones del valle medio o estas quebradas laterales. Justamente en estos lugares se van a establecer primero pequeños asentamientos que recepcionarán a los visitantes, habilitándose áreas ceremoniales y finalmente al adquirir mayor prestigio, van a tener un crecimiento notable. Esto es lo que sucede en Cajamarquilla, cuya importancia empieza a crecer desde finales del Periodo Intermedio Temprano, logrando su mayor expansión en el Periodo Intermedio Tardío.

Existen otros sitios en las quebradas que se unen a los valles de Lima que cumplían la misma función que Cajamarquilla; entre estos tenemos a Huaycán de Pariachi, la cual se ubica en la parte baja de una quebrada amplia por donde fácilmente se comunica con el valle medio de Lurín (Cieneguilla). En el valle del Chillón, un caso similar puede ser la Fortaleza de Collique, ubicado en la quebrada de Collique, el cual es un corredor natural hacia la quebrada de Lurigancho. Es posible que algunos sitios de esta quebrada de Lurigancho también hayan tenido esta importancia como Mangomarca o Campoy. 
La quebrada de Jicamarca es extensa, tiene alrededor de $36.2 \mathrm{~km}$ de largo y 3.47 $\mathrm{km}$ de ancho cerca de su desembocadura y alrededor de 1 kilómetro en la mayoría de su trazo. Es un corredor natural por donde en un día de camino (en promedio), se llega a la cabecera de la quebrada, desde donde se puede acceder al territorio de otras formaciones sociopolíticas como los Chaclla (cuenca alta del río Santa Eulalia) o los Araguay (cuenca alta del río Chillón). Las investigaciones realizadas en este territorio (Casaverde, 2016) han identificado para periodos prehispánicos tardíos la existencia de caminos que articulan estos dos territorios con otras zonas más lejanas, articulándose con otras vías como el Qhapaq Ñan en sus caminos de penetración costa-sierra. Es decir, ascendiendo (o viceversa) por la quebrada de Jicamarca se puede llegar fácilmente y en menor tiempo, a la cuenca alta del río Chillón y desde aquí acceder mediante la cordillera de La Viuda al territorio de Chinchaycocha y Pasco y posiblemente desde aquí a la Amazonía. Pero si desde la cabecera de la quebrada de Jicamarca se toma rumbo al sur se accede a través del territorio de los Chacllas al valle de Santa Eulalia, desde donde se accede a través del camino de penetración a las alturas de Yauli (Marcapomacocha) y desde aquí se comunica fácilmente con el valle del Mantaro. Esto significa transitar por territorios no solo de diversos grupos culturales, sino de diversas divinidades, como Huayayo Carhuincho.

En este sentido, la quebrada de Jicamarca fue en periodos prehispánicos tardíos un área donde llegaban personas procedentes de diversos grupos culturales, quienes llegaban a Cajamarquilla para realizar el intercambio de productos altoandinos con productos costeños. Así, Cajamarquilla adquirió no solo un gran poder económico, sino también religioso, pues los encuentros o tinkuys se realizaban en medio de grandes ceremonias religiosas, dando paso luego al intercambio.

Por ello, pensamos que, durante el Periodo Intermedio Tardío, Cajamarquilla se convirtió en un centro comercial multiétnico, donde residían personas de diversos grupos étnicos, aunque principalmente población local (ichma periférica) y chacllas dedicados a esta actividad cultural.

Si bien es cierto, las investigaciones arqueológicas han determinado que el valle medio inferior del Rímac formó parte del territorio Ichma durante el Periodo Intermedio Tardío, la ubicación de esta zona (al igual como la sección baja de la quebrada de Jicamarca donde se ubica Cajamarquilla) en una zona periférica del territorio cultural Ichma, permitió que desarrolle ciertas características propias, recibiendo la influencia de otras sociedades contiguas, como los Chaclla. Por ello, no es de extrañar lo señalado por los manuscritos de Huarochirí recopilados por Ávila en el siglo XVII (Taylor, 1987) donde indican que los huarochiranos dirigidos por Tutayquiri invadieron todo el valle medio del Rímac. También Miguel Cornejo (2000, p. 154) citando a Rostworowski y a Espinoza señala que los Chacllas conquistaron Carapongo, Huampaní y Huachipa. La presencia de los Chacllas en el Horizonte Tardío en esta 
sección del valle del Rímac es también identificada por Dolorier (2017), quien ha identificado ocupaciones Chacllas en los alrededores de Carapongo, aunque los define como mitqmas. Estos Chacllas, cuyo territorio en el Periodo Intermedio Tardío se extendía hasta la sección alta de la quebrada de Jicamarca, conocían muy bien el territorio de toda la quebrada hasta su desembocadura al Rímac, incluyendo el área de Cajamarquilla. Lamentablemente, la falta de investigaciones arqueológicas en la parte media y alta de la quebrada de Jicamarca no permite conocer la existencia de sitios arqueológicos de este periodo que permitan corroborar estas propuestas, lo cual queda pendiente para los próximos años.

Pedro Villar Córdova (1935) señala que Cajamarquilla, antiguamente llamado Lurin Jicamarca estuvo ocupado hasta los momentos de la invasión española, siendo reducido junto a otros pueblos contiguos en el pueblo hispano de Jicamarca (en la actual provincia de Huarochirí, pero a pocos km del sitio arqueológico); lo cual corroboraría las relaciones serrano-costeñas existentes en esta zona. Muchos comuneros de las comunidades de Chaclla y Jicamarca hasta hace pocos años descendían con su ganado en calidad de pastores o arrieros por esta quebrada para aprovechar las lomas que brindaban alimentos a su ganado, estableciendo corrales y estancias durante dos o tres meses (invierno en la Costa) para luego retornar estacionalmente a sus comunidades de origen. Algunas referencias históricas señalan que durante la Colonia, comerciantes de hielo descendían con caballos y mulas cargadas de hielo traído desde las cordilleras nevadas de La Viuda para abastecer de hielo a la ciudad de Lima.

El uso intensivo del tapial en Cajamarquilla obedece a un símbolo de status, pues esta técnica constructiva va a aparecer en la Costa hacia finales del Periodo Intermedio Temprano, intensificándose su uso hacia el Horizonte Medio y Periodo Intermedio Tardío. La elaboración de tapiales en Cajamarquilla no era complicada, tomando en cuenta que se aprovechó las gruesas capas de yapana que cubren el cauce de la quebrada, producto de la deposición geológica de numerosos eventos de huaycos sucedidos en los últimos cien mil años, considerando que, en gran parte de los periodos prehispánicos, el cauce de la quebrada se encontraba activa, con considerables cargas de agua que descendían desde las partes altas de las quebradas.

Las evidencias identificadas y registradas en el sector Tello de Cajamarquilla son también extensivas a muchos otros sectores que presentan las mismas características; por ello es que planteamos que, durante el Periodo Intermedio Tardío, se dio la mayor expansión urbanística del sitio de Cajamarquilla, estrechamente relacionado con las esferas de interacción interregional basadas en la actividad comercial, tal como se venía dando desde el Intermedio Temprano y Horizonte Medio (Shady, 1982). Actividad que le dio mayor prestigio e importancia en toda la sección del valle del Rímac, como puerta de entrada a las poblaciones costeñas. La presencia de gran- 
des recintos, áreas de depósitos y silos subterráneos donde se almacenaban grandes cantidades de productos que llegaban de regiones lejanas para ser intercambiadas, apoya esta hipótesis.

Dejamos sentado en este punto que futuras investigaciones con excavaciones en el sitio van a ayudar a esclarecer la problemática del Periodo Intermedio Tardío en Cajamarquilla; pues las áreas intervenidas en los últimos años por Juan Mogrovejo, Rafael Segura y Joaquín Narváez son mínimas extensiones. Las mayores excavaciones en el sector Tello de las últimas décadas fueron realizadas por Dante Casareto, pero aún no han sido publicadas. Por ello, hay muchas preguntas que aún nos quedan, como el hecho de que no hayan sido reportadas aún pirámides con rampa en Cajamarquilla, patrón característico de los sitios Ichma, la poca densidad de cerámica de estilo Ichma recuperado en las excavaciones, entre otros. Esperamos en los próximos años realizar excavaciones para tener un panorama más esclarecedor.

\section{CONCLUSIONES}

Las investigaciones realizadas en el sector Tello, nos han permitido presenciar, el crecimiento y desarrollo a través de la arquitectura del tapial, de un momento de ocupación relacionado al Intermedio Tardío, correspondiente a la cultura Ychsma. Esta ocupación tardía del sector Julio C Tello, está representada por la arquitectura del tapial (en muros y banquetas), así como muros de yapana. Esta ocupación tardía está conformada por recintos asociados a patios, articulados por pasadizos y calles, con remodelaciones arquitectónicas en la cima de la pirámide.

Durante el Horizonte Medio el sector Julio C. Tello de Cajamarquilla tuvo un pequeño momento de ocupación y no fue un sitio que solo fue construido por el supuesto "Imperio Huari", y que posterior a este fue abandonado (por la presencia de acumulación de arena) y reutilizado solo como cementerio. El uso intensivo del tapial en Cajamarquilla obedece a un símbolo de status. La elaboración de tapiales en Cajamarquilla no era complicada, tomando en cuenta que se aprovechó las gruesas capas de yapana que cubren el cauce de la quebrada para su elaboración.

Durante el Periodo Intermedio Tardío, Cajamarquilla se convirtió en un centro comercial multiétnico, donde residían personas de diversos orígenes étnicos, siendo los más recurrentes las poblaciones locales (ichmas) y chacllas dedicados a esta actividad cultural. La diferenciación de sectores obedecería a diversos centros comerciales y cultistas pertenecientes a diferentes linajes que coexistieron a través del Periodo Intermedio Tardío.

La trascendencia de Cajamarquilla radica en su ubicación, cerca de la desembocadura de una de las quebradas afluentes más grandes del valle medio del Rímac, muy cerca al cono de deyección del valle. Esta ubicación es estratégica, como control y medio de interacción de las relaciones interregionales. 
Agradecimientos: Un especial agradecimiento al Vicerrectorado de Investigación y Posgrado de la Universidad Nacional Mayor de San Marcos, por el financiamiento como parte de los trabajos de investigación para obtener el grado de bachiller. A mi asesor el Dr. Pieter van Dalen Luna, por su constante apoyo, exigencia y motivación para la realización de este trabajo de investigación, a mis queridos profesores que me apoyaron durante 5 años, en especial a Francisco Medina quien fue uno de los primeros en apoyarme con el tema de Cajamarquilla. Agradecer a mis queridos padres, hermanos por su apoyo emocional y económicamente durante todo este tiempo, y a mis queridas amistades quienes fueron cómplice en varias salidas de campo entre ellas Noelia Allcca, muy agradecida con todos.

\section{REFERENCIAS BIBLIOGRÁFICAS}

Abanto, J. (2008). Lurigancho, un curacazgo Ychsma de la margen derecha del valle bajo del Rímac. Arqueología y Sociedad, (19), 159-178. Lima: Museo de Arqueología y Antropología de la Universidad Nacional Mayor de San Marcos.

Agurto Calvo, S. (1984). Lima Prehispánica. Lima: Municipalidad de Lima.

Bazán, F. (1990). Arqueología y etnohistoria de los periodos prehispánicos tardíos de la Costa Central del Perú. Tesis para optar el título profesional de licenciado en arqueología. Lima: Universidad Nacional Mayor de San Marcos.

Bonavía, D. (1965). Arqueología de Lurín. Seis estilos de ocupación en la parte inferior del valle. Serie Tesis antropológicas, 4. Lima: Publicaciones del Museo Nacional de Cultura Peruana.

Bueno Mendoza, A. (1974). La zona Arqueológica de Cajamarquilla, valle del Rímac. Revista Proceso, (4), p. 1721. Órgano Cultural de la Universidad Nacional del Centro. Huancayo, Junín.

Bueno Mendoza, A. (1974-75). Cajamarquilla y Pachacámac: Dos ciudades de la Costa Central del Perú. XXXIX Congreso Internacional de Americanistas. Boletín Bibliográfico de Antropología Americana, 37(46), p. 171-201. México.

Cáceres, B. (2021). Una aproximación a la gestión cultural en el sitio arqueológico de Cajamarquilla, Lima-Perú. Arqueología y Sociedad, (33), 271-291. Lima: Museo de Arqueología y Antropología, Universidad Nacional Mayor de San Marcos.

Canziani, J. (2009). Ciudad y territorio en los Andes. Contribuciones a la historia del urbanismo prehispánico. Pontificia Universidad católica del Perú. Lima.

Casareto, D. (1999). Informe final del Proyecto Arqueológico Cajamarquilla. Temporada 1998. Informe presentado al Instituto Nacional de Cultura. Sociedad Minera Refinería de Zinc de Cajamarquilla S.A., Fundación Augusto N. Wiese. 
Casareto, D. (2000). Informe final del Proyecto Arqueológico Cajamarquilla. Temporada 1999. Informe presentado al Instituto Nacional de Cultura. Sociedad Minera Refinería de Zinc de Cajamarquilla S.A., Fundación Augusto N. Wiese.

Casas, L. (2017). La zona de Carapongo como expresión física de una entidad política, durante el período de los Reinos y Señoríos Tardíos. Tesis para optar el Grado Académico de Magíster en Arqueología Andina. Lima: Universidad Nacional Mayor de San Marcos.

Cornejo, M. (2000). La nación Ischma y la provincia Inka de Pachacamac. Arqueológicas, (24), 147 - 173. Museo de Arqueología, Antropología e Historia del Perú.

D’Harcourt, R. (1922). La ceramique de Cajamarquilla - Nievería. Journal de la Societe des Americanistes, (14), 107-118. París.

Díaz Arriola, L. (2008). Aproximaciones hacia la problemática del territorio Ychsma. Arqueología y Sociedad, (19), 115-128. Lima: Museo de Arqueología y Antropología de la Universidad Nacional Mayor de San Marcos.

Dolorier, C. (2017). Presencia de Mitmas Chaclla en la zona de Carapongo del valle bajo del Rímac durante la época inca. Tesis para optar el Grado Académico de Magíster en Arqueología Andina. Universidad Nacional Mayor de San Marcos. Lima.

Franco, R. (1998a). Cajamarquilla. La arquitectura de un Gran Centro Prehispánico de la Costa Central. Arkinka, (36), 72-89. Lima.

Franco, R. (1998b). La pirámide con Rampa No 2 de Pachacámac. Excavaciones y Nuevas Interpretaciones. Trujillo.

Iriarte, F. (1960). Algunas apreciaciones sobre los guanchos. Antiguo Perú, espacio y tiempo (pp. 259-263). Lima.

Ludeña, H. (1975). Secuencia cronológica cultural del valle del Chillón. Tesis para optar el grado de Doctor. Lima: Universidad nacional Mayor de San Marcos.

Lumbreras, L. (1974). Las Fundaciones de Huamanga. Club Huamanga. Lima.

Lumbreras, L. (1981). La arqueología como ciencia social. Ediciones Peisa. Lima.

Lumbreras, L. (1988a). La Arqueología de la América Andina. Editorial Milla Batres.

Lumbreras, L. (1988b). El estudio arqueológico del Estado. Gaceta Arqueológica Andina, (16), 3-5. Lima.

Makowski, K. (2001). Las civilizaciones prehispánicas en la costa central y sur. Historia de la cultura peruana I, (pp. 163-244). Fondo Editorial del Congreso del Perú. Lima.

Menzel, D. (1968). La cultura Huari. Las grandes civilizaciones del antiguo Perú. Tomo IV. Compañía de Seguros y Reaseguros Peruano, Suiza S.A. 
Middendorf, E. (1974). Perú. Observaciones y estudios sobre el país y sus habitantes durante una de 25 años. Universidad Nacional mayor de San Marcos. (Original publicado en 1877).

Mogrovejo, J. (1997). Informe final de la temporada de las investigaciones 1997 en el conjunto Julio C. Tello, Cajamarquilla. Informe presentado al Instituto Nacional de Cultura, Proyecto Arqueológico Cajamarquilla. Lima.

Mogrovejo, J. y Makowski, K. (1999). Cajamarquilla y los meganiños en el pasado prehispánico. Íconos (1), 46-57. Lima: Pontificia Universidad Católica del Perú.

Mogrovejo, J. y Segura, R. (2000). El Horizonte Medio en el Conjunto Arquitectónico Julio C. Tello de Cajamarquilla. Boletín de Arqueología PUCP, (4), Huari y Tiwanaku: Modelos vs. Evidencias (pp. 565-582). Fondo Editorial PUCP. Lima.

Morales, D. (1993). Historia arqueológica del Perú. Del Paleolítico al Imperio Inca. En Compendio Histórico del Perú, Tomo I. Ed. Milla Batres. Lima:

Mogrovejo, J. D. y Makowski, K. (1999). Cajamarquilla y los Mega Niños del Pasado prehispánico. En Iconos, (1), 46-57. Instituto Superior de Conservación Yachay Wasi. Lima.

Mogrovejo, J. D. y Segura, R. (2000). El Horizonte Medio en el Conjunto Arquitectónico Julio C. Tello de Cajamarquilla. Boletín de Arqueología PUCP, (4), Huari y Tiwanaku: Modelos vs. Evidencias (565-582). Pontificia Universidad Católica del Perú. Lima.

Narváez, J. (2004). Investigaciones arqueológicas en Cajamarquilla, Excavación en el Sector XI del conjunto Tello y la importancia de ocupación Ychsma en Cajamarquilla. Tesis para optar el título de licenciado en arqueología. Universidad Nacional Mayor de San Marcos.

Narváez, J. (2005). Sociedades de la antigua ciudad de Cajamarquilla: investigaciones arqueológicas en el sector XI del Conjunto Tello y un estudio de la colección tardía del Conjunto Sestieri. Lima.

Narváez, J. (2013). Pre-colonial Irrigation and Settlement Patterns in Three Artifi cial Valleys in Lima - Peru. Tesis de doctorado. University of Calgary. Department of Archaeology. Calgary Canada.

Patterson, T. (2014). Patrón y proceso en la cerámica del Periodo Intermedio Temprano de la Costa central del Perú. Avqi editores. Lima.

Ravines, R. (1989). Introducción a una bibliografía general de la arqueología del Perú (18601988). Editorial Los Pinos. Lima.

Rostworowski De Diez Canseco, M. (2018). Costa peruana prehispánica. Lima: Instituto de Estudios Peruanos. 
Segura, R. (2001). Rito y economía en Cajamarquilla: investigaciones arqueológicas en el conjunto arquitectónico Julio C. Tello. Pontificia Universidad Católica del Perú. Lima.

Sestieri, C. (1964). Excavations at Cajamarquilla, Perú. Archaeology, 17(1), 12-17.

Sestieri, C. (1971). Cajamarquilla, Perú: The necropolis on the Huaca Tello. Archaeology, 24(2), 101-106.

Sestieri, C. (1972). Scavi a Cajamarquilla (Perú). Atti del XL Congresso Internacionale degli americanistas, (esttrato). Roma - Genova.

Shady, R. (1982). La Cultura Nievería y la interacción social en el mundo andino en la época Huari. Arqueológicas (19), 5-18. Museo Nacional de Antropología y Arqueología. Lima.

Squier, G. (1974 [1877]). Un viaje por tierras incaicas. Crónica de una expedición arqueológica (1863-1865). Universidad Nacional Mayor de San Marcos y Embajada de los Estados Unidos.

Stumer, M. L. (1954). Antiguos centros de la población del valle de Rímac. Revista del Museo Nacional (23), 212-240. Lima.

Taylor, G. (1987). Ritos y tradiciones de Huarochirí del siglo XVII. Instituto de Estudios Peruanos. Lima.

Tello, Julio C. (1999). Arqueología del valle de Lima. Cuadernos de Investigación del Archivo Tello, 1. Museo de Arqueología y Antropología de la Universidad Nacional Mayor de San Marcos.

van Dalen, P. (2012a). Análisis de la costa central peruana descrita por Garcilaso de la vega en los Comentarios reales de los Incas. Kullpi: investigaciones culturales en la provincia de Huaral y el Norte Chico, (6), 149-174. Lima.

van Dalen, P. (2012b). Análisis arquitectónico y secuencias de ocupación en el sitio de Pampa de Animas - La Wasa, Luriama, campiña de Santa María, valle de Huaura. Kullpi: investigaciones culturales en la provincia de Huaral y el Norte Chico, (6), 67-117. Lima.

van Dalen, P. (2012c). Arqueología de la chaupiyunga baja del valle Chancay-Huaral. Un análisis del territorio intermedio entre los Chancay y Atavillos. Tiempos. Revista de historia y cultura, (7), 11-40. Lima.

van Dalen, P. (2013). Arqueología tardía del valle Chancay - Huaral: identificando la nación Chancay. Investigaciones Sociales, (28), 271-284. Lima.

van Dalen, P. (Ed). (2014). Arqueología de las cuencas alto y medio andinas del departamento de Lima. Universidad Nacional Mayor de San Marcos. 
Villacorta, L. (2004). Los palacios en la costa central durante los periodos tardíos: de Pachacamac al Inca. Bulletin de l'Institut Français d'Etudes Andines, 33(3), 539570. Lima: Instituto Francés de Estudios Andinos.

Villacorta, L. (2003). Palacios y ushnus: curacas del Rímac y gobierno inca en la costa central. Boletín de Arqueología PUCP, (7), 151-187. Lima: Pontificia Universidad Católica del Perú. Lima.

Villar Córdova, P. (1938). Las ruinas de Cajamarquilla. Lima precolombina y virreinal (pp. 49-56). Lima.

\section{SOBRE LA AUTORA}

\section{Yomira Silvia Huaman Santillan}

Egresada en Arqueología en la Universidad Nacional Mayor de San Marcos. Dirigió la investigación: "Cajamarquilla, identificación de su máxima extensión a través de la arquitectura del tapial en el Periodo Intermedio Tardío" (E2015007c), proyecto ganador del Programa de Promoción de trabajo de investigación para optar el grado de Bachiller, del Vicerrectorado de Investigación y Posgrado de la Universidad Nacional Mayor de San Marcos. Actualmente se desempeña como arqueóloga de campo y gabinete en el Proyecto Arqueológico La Huaca. 